\title{
Salidroside contributes to reducing blood pressure and alleviating cerebrovascular contractile activity in diabetic Goto-Kakizaki Rats by inhibition of L-type calcium channel in smooth muscle cells
}

Yu-Guang $\mathrm{Ma}^{1+}$, Jun-Wei Wang ${ }^{2+}$, Yun-Gang Bai ${ }^{3}$, Mei Liu' ${ }^{1}$, Man-Jiang Xie ${ }^{3^{*}}$ and Zhi-Jun Dai ${ }^{{ }^{*}}$

\begin{abstract}
Background: Vascular disease is a common and often severe complication in diabetes mellitus. Hyperglycemia and hypertension are considered to be two of the leading risk factors for vascular complications in diabetic patients. However, few pharmacologic agents could provide a combinational therapy for controlling hyperglycemia and blood pressure in diabetic patients at the same time. Salidroside $(S A L)$ is the major active ingredient derived from Rhodiola. Recently, it has been reported that SAL have an obvious hypoglycemic effect in diabetes and show a beneficial activity in diabetic vascular dysfunction. However, it remains unknown whether or not SAL treatment could directly reduce blood pressure in diabetes. Furthermore, it is not clear what is the molecular mechanism underlying the vascular protection of SAL treatment in diabetes.
\end{abstract}

Methods: Male diabetic Goto-Kakizaki (GK) and non-diabetic control Wistar-Kyoto (WKY) rats were administrated with different dosages of SAL (50, 100 and 200 mg/kg/day) for 4 weeks. Contractile responsiveness of cerebral artery to $\mathrm{KCl}$ or $5-\mathrm{HT}$ was investigated by Pressure Myograph System. The activity of $\mathrm{Ca}_{\mathrm{L}}$ channel was investigated by recording whole-cell currents, assessing the expressions of CaL channel $a_{1} c_{-}$-subunit and its downstream kinase, MLCK, at protein or mRNA levels.

Results: We showed that administration of $100 \mathrm{mg} / \mathrm{kg} /$ day SAL for 4 weeks not only lowered blood glucose, but also reduced blood pressure and alleviated cerebrovascular contractile activity in diabetic GK rats, which suggested that SAL treatment may provide a combinational therapy for lowering blood glucose and reducing blood pressure in diabetes at the same time. Furthermore, SAL treatment markedly inhibited the function and expression of Ca channel in cerebral VSMCs isolated from diabetic GK rats or when exposed to hyperglycemia condition, which may be the underlying mechanism responsible for the vascular protection of SAL in diabetes.

Conclusions: The present study provided evidences that SAL contributes to reducing blood pressure and alleviating cerebrovascular contractile activity in diabetic GK rats by inhibition of $C_{L}$ channel in smooth muscle cells, which may provide a novel approach to treat vascular complications in diabetic patients.

Keywords: Salidroside, Contractile activity, Vascular smooth muscle cells (VSMCs), L-type Ca ${ }^{2+}$ channel (CaL)

\footnotetext{
*Correspondence: manjiangxie@hotmail.com; dzj0911@126.com

${ }^{\dagger}$ Equal contributors

${ }^{3}$ Department of Aerospace Physiology, Key Laboratory of Aerospace

Medicine of Ministry of Education, Fourth Military Medical University, Xi'an

710032, Shaanxi Province, China

'Department of Oncology, The Second Affiliated Hospital of Medical College,

Xi'an Jiaotong University, Xi'an, Shaanxi Province 710004, China

Full list of author information is available at the end of the article
} 


\section{Background}

Vascular disease is a common and often severe complication in diabetes mellitus (DM) for it significantly increases the risk for heart attack, stroke, retinopathy, nephropathy, neuropathy, and diabetic foot disorders. Diabetic vascular complication is usually characterized by the increased vascular resistance, augmented contractile activity, impaired endothelium-dependent vasodilatation, increased oxidative stress, enhanced inflammation, and progressive atherosclerosis $[1,2]$. The clustering of risk factors could accelerate the progression of diabetic vascular complication, such as hyperglycemia, high blood pressure, dyslipidaemia, insulin resistance, smoking, and obesity. There is evidence from large randomized-controlled trials that good glycemic control in both type 1 and 2 DM can delay the onset and progression of diabetic vascular complication [3, 4]. In addition, it has also been shown that the aggressive blood pressure control could significantly reduce the risk for stroke, heart failure, retinopathy, and nephropathy in DM [5-7]. At present, most diabetic patients with elevated blood pressure will require two or more agents to decrease hyperglycemia and lower blood pressure. However, few pharmacologic agents could provide a combinational therapy for controlling hyperglycemia and blood pressure in diabetic patients at the same time.

As a well-known traditional herb medicine, Rhodiola rosea (Rhodiola) has been demonstrated to have beneficial effects for high altitude-related symptoms [8]. Recently, it has been reported that Salidroside (SAL), the major active ingredient derived from Rhodiola, has multiple pharmacological activities, such as attenuating hypoxia [9], alleviating chronic hypoxic-induced pulmonary arterial hypertension [10], anti-oxidation [11, 12], anti-inflammation [13-15], anti-cancer, enhancing immune effects, and neuro-/ hepato-/cardiovascular protection [16-18]. It is notable that several experimental and clinical studies have provided evidences that SAL was found to dramatically reduce blood glucose and serum insulin levels $[9,12]$, ameliorate insulin resistance [9], alleviate diabetic albuminuria [19], and stimulate glucose uptake in skeletal muscle cells [20]. Extensive studies suggested that SAL also showed the beneficial protection on vasodilatation in Goto-Kakizaki (GK) diabetic rats [21]. All these findings suggested that the potential efficacy of SAL might be additionally used for the treatment of diabetic vascular complication. However, it remains unknown whether or not SAL treatment could directly reduce blood pressure in diabetes. Furthermore, it is not clear what is the molecular mechanism underlying the vascular protection of SAL treatment in diabetes.

Vascular contractile activity, an important determinant of blood pressure, is mainly regulated by both $\mathrm{Ca}^{2+}$-independent and $\mathrm{Ca}^{2+}$-dependent mechanisms in vascular smooth muscle cells (VSMCs). The calcium-independent pathway of vascular contraction is mediated by the GTPase RhoA and Rho kinase. Particularly, increases in intracellular $\mathrm{Ca}^{2+}$ from receptor- or ion channel-activated pathways are the primary triggers to activate myosin light chain kinase (MLCK), which phosphorylates myosin light chains (MLC) and then activating myosin ATPase and leading to vascular contraction. It is considered that arterial contractility and vascular tone are predominantly controlled by membrane potential and $\mathrm{Ca}^{2+}$ influx via long-lasting voltage-dependent $\mathrm{Ca}^{2+}$ (L-type, $\mathrm{Ca}_{\mathrm{L}}$ ) of VSMCs [1, 22]. Evidences from human and animal studies indicated that diabetic vascular complication with elevated blood pressure is tightly coupled to the impaired $\mathrm{Ca}_{\mathrm{L}}$ channels in VSMCs $[1,23]$. Therefore, $\mathrm{Ca}_{\mathrm{L}}$ channel and its downstream molecules could be the important therapeutic targets in diabetic vascular complications [1].

This study was 1) to investigate the effects of SAL treatment on blood pressure and cerebrovascular contractile activity independent of a functional endothelium in diabetic Goto-Kakizaki (GK) rats; 2) to investigate the effects of SAL on $\mathrm{Ca}_{\mathrm{L}}$ channels of cerebral VSMCs in diabetic GK rats or when exposed to hyperglycemia condition by recording whole-cell $\mathrm{Ca}_{\mathrm{L}}$ currents, assessing the expressions of $\mathrm{Ca}_{\mathrm{L}}$ channel $\alpha_{1 \mathrm{C}}$-subunit and one of its downstream kinases, MLCK, at protein or mRNA levels. Taken together, this study provided evidences for the first time that SAL contributes to reducing blood pressure and alleviating cerebrovascular contractile activity in diabetic GK rats by inhibition of $\mathrm{Ca}_{\mathrm{L}}$ channel in smooth muscle cells, which may provide a novel approach to treat vascular complications in diabetic patients.

\section{Methods}

\section{Animal model}

Male diabetic Goto-Kakizaki (GK) rats (aged 18 weeks, $n=70$ ) and non-diabetic control Wistar-Kyoto (WKY) rats (aged 18 weeks, $n=70$ ) were purchased from the shanghai laboratory animal center of Chinese Academy of Science (Shanghai, China).

Goto-Kakizaki rats are a Wistar substrain and that Wistar-Kyoto rats are a reasonably matched control strain. After an adaptive feeding for 2 week, rats (20 weeks of age) were divided into 4 groups: control WKY rats (WKY), WKY rats administered with SAL (WKY + SAL), diabetic GK rats, and diabetic GK rats administered with SAL (GK + SAL). Experiment I, Experiment II, and Experiment III were designed to investigate the different dosages of SAL (50, 100 and $200 \mathrm{mg} / \mathrm{kg} /$ day) on blood glucose, blood pressure, and contractile activity of cerebral artery in diabetic GK rats. SAL was dissolved in DMSO to a stock concentration and then stored at $-20{ }^{\circ} \mathrm{C}$. SAL was intragasriclly administered daily 
for 4 weeks. The control groups were administrated with equal volume of vehicles. The dosage of SAL was based on the previous reports [12]. Fasting blood glucose was measured by glucose oxidase/peroxidase method and blood pressure was measured by the tail-cuff method [24]. Four weeks after SAL treatment, animals were anesthetized and then killed by exsanguination. All groups were caged individually in a room temperature of $23^{\circ} \mathrm{C}$.

\section{Examination of contractile activity}

As previously described [25], the middle cerebral artery was obtained and the endothelial layer was removed by the injection of air bubbles. The artery was cannulated in a chamber [26] and then transferred to the Pressure Myograph System P110 (DMT, Denmark). After equilibration of $50 \mathrm{mmHg}$ for $1 \mathrm{~h}$ at $37^{\circ} \mathrm{C}$, the contractile response to cumulative superfusion of $\mathrm{KCl}$ or $5-\mathrm{HT}$ was determined as the percentage of luminal diameter relative to the baseline internal diameter.

\section{Isolation of VSMCs}

Isolated VSMCs were obtained as described previously [27]. Briefly, the cerebral arteries including superior, middle, and basilar arteries were digested for $18 \mathrm{~min}$ at $37{ }^{\circ} \mathrm{C}$ with $4 \mathrm{mg} / \mathrm{ml}$ papain (Biochrom, Berlin, Germany), $2 \mathrm{mg} / \mathrm{ml}$ dithioerythritol (Amresco, St. Louis, Missouri, USA), $1 \mathrm{mg} / \mathrm{ml}$ bovien serum albumin (BSA), and $5 \mathrm{mM}$ taurine. Isolated VSMCs were maintained in $\mathrm{Ca}^{2+}$-free PSS at $4{ }^{\circ} \mathrm{C}$ for use within $8 \mathrm{~h}$.

\section{Electrophysiological measurements}

Whole-cell $\mathrm{Ca}_{\mathrm{L}}$ channel currents were measured with the conventional voltage clamp configuration [28]. There were two kinds of external solutions, i.e., solution $A$ and B. Solution $A$ contained (in $\mathrm{mM}$ ) $130 \mathrm{NaCl}, 5.4 \mathrm{KCl}, 1$ $\mathrm{MgCl}_{2}, 10 \mathrm{BaCl}_{2}, 10 \mathrm{HEPES}$, and 10 glucose, equilibrated with 95\% $\mathrm{O}_{2}$ and $5 \% \mathrm{CO}_{2}$ at $\mathrm{pH} 7.4$ adjusted with $\mathrm{NaOH}$. After a seal of $2 \mathrm{G} \Omega$ was obtained, solution $B$ was changed which contained (in mM) 75 Tris- $\mathrm{Cl}, 50$ $\mathrm{BaCl}_{2}, 10 \mathrm{HEPES}$, and 10 glucose, equilibrated with 95\% $\mathrm{O}_{2}$ and $5 \% \mathrm{CO}_{2}$ at $\mathrm{pH} 7.4$ titrated with Tris base. The pipette solution contained $150 \mathrm{CsCl}, 1 \mathrm{MgCl}_{2}, 10 \mathrm{EGTA}$, 5 HEPES, $5 \mathrm{Na}_{2} \mathrm{ATP}$, and $5 \mathrm{Na}_{2}$ creatine phosphate, equilibrated with $95 \% \mathrm{O}_{2}$ and $5 \% \mathrm{CO}_{2}$ at $\mathrm{pH} 7.2$ titrated with $\mathrm{CsOH}$. All measurements were carried out at room temperature $\left(22-24{ }^{\circ} \mathrm{C}\right)$.

\section{Evaluation the protein expression of $\mathrm{Ca}_{\llcorner}$channel by Western blotting}

According to our previous report [28], the protein sample of cerebral artery was run for SDS-PAGE for $80 \mathrm{~min}$ at 30 $\mathrm{mA}$ with a $8 \%$ Tris-Glycine gel (Invitrogen, Carlsbad, California, USA). After separation, proteins were transferred onto a nitrocellulose membrane and then blocked overnight at $4{ }^{\circ} \mathrm{C}$. The membranes were incubated with rabbit polyclonal antibody against the $\mathrm{Ca}_{\mathrm{L}}$ channel $\alpha_{1 C}$-subunit (Alomone Labs, Jerusalem, Israel) and subsequently incubated with Infrared (IR)-labeled secondary antibodies (LI-COR). A monoclonal mouse antibody raised against $\beta$-actin (Sigma) was used as a lane-loading control. The bound antibody was detected by the Odyssey infrared imaging system (LI-COR). Densitometry analysis of bands was performed by Scion image (Scion, Frederick, MD).

\section{Cell culture}

As previously described [29], isolated VSMCs were cultured in DMEM (GIBCO, USA) supplemented with 20\% FBS (HyClone, USA). To diminish the interferences of serum, the VSMCs were cultured in 5\% FBS $+3 \%$ Insulin-Transferrin-Selenium (ITS) during the pharmacological experiments. The cells at passages $5-8$ were used for experimentations.

\section{Evaluation the mRNA expression of $\mathrm{Ca}_{\mathrm{L}}$ and MLCK by Real-Time PCR}

As described previously [30], total RNA was extracted from cerebral arteries or cultured VSMCs with TRIzol reagent (Invitrogen) according to manufacturer's protocol. The concentration of RNA were determined by assessing the absorbance at 260 and $280 \mathrm{~nm}$. Then RNA was reverse-transcribed into cDNA using Primerscript RT Kit (TaKaRa Biotechnology, Dalian, China). Real-time quantitative PCR analysis was performed on an ABI 7500 real-time PCR system (Applied Biosystems) using SYBR Premix Ex TaqII Kit (Takara, Japan). The endogenous $\beta$-actin was used to evaluate the efficiency of reverse transcription. Cycle conditions were as follows: $95{ }^{\circ} \mathrm{C}$ for $30 \mathrm{~s}$ followed by 40 cycles $\left(95{ }^{\circ} \mathrm{C}\right.$ denaturation for $5 \mathrm{~s}, 60{ }^{\circ} \mathrm{C}$ annealing for $30 \mathrm{~s}$ ). A relative quantification method $\left(2^{-\triangle \Delta C T}\right.$, where $\mathrm{Ct}$ is cycle threshold) was chosen for quantitative analysis. The relative quantitation value of target, normalized to the endogenous control $\beta$-actin. The primers pairs of $\mathrm{Ca}_{v} 1.2$ : Forward-5' -TGC TGT GTC TGA CCC TGA AG-3' and Reverse-5'-CGT CTT CCG GAA AGG GAA TA-3'. The primers pairs of MLCK: Forward-5'-GAC GTG TTC ACC CTG GTT CT-3' and Reverse-5' -TTT GTG CAG CAT CAG TGA CA-3'. The primers pairs of $\beta$-actin were Forward-5' -TCA GGT CAT CAC TAT CGG CAAT-3' and Reverse-5'-AAA GAA AGG GTG TAA AAC GCA-3'.

\section{Statistical analysis}

Followed by a S-N-K-Post Hoc, the differences of $\mathrm{Ca}_{\mathrm{L}}$ channel current densities were determined by one-way ANOVA in different groups. The differences of body weights, blood glucose, the resting $\mathrm{Ca}^{2+}$ fluorescence intensity, and the maximal increase of $\mathrm{Ca}^{2+}$ fluorescence 
intensity were determined by Student's $t$-test in different groups. A value of $P \leq 0.05$ was used for the statistically significant.

\section{Results}

\section{Physical characteristics of experimental animals}

The GK rat is a spontaneous diabetic animal model with elevated blood glucose, peripheral insulin resistance, and a non-obese phenotype. In the present study, the levels of blood glucose significantly increased in diabetic GK rats, whereas there was no significant different in the body weights between age matched control WKY and diabetic GK rats, which were in consistence with previous report [21, 31, 32]. In Experiment I, $50 \mathrm{mg} / \mathrm{kg} /$ day SAL for 4 weeks had no obvious effects on blood glucose in WKY or GK rats, respectively, which indicated that $50 \mathrm{mg} / \mathrm{kg} /$ day SAL is not an effective dosage for reducing blood glucose in diabetic GK rats. In Experiment II, $100 \mathrm{mg} / \mathrm{kg} /$ day SAL for 4 weeks markedly decreased the blood glucose of diabetic GK rats and had no obvious effects in control WKY rats, which is well in accordance with earlier reports $[9,15,19]$. However, there was also a significant difference in the blood glucose between GK + SAL and WKY rats, which indicated that SAL treatment did not restore the blood glucose to the normal control level. In Experiment III, chronic administration of $200 \mathrm{mg} / \mathrm{kg} /$ day SAL for 4 weeks significantly decreased blood glucose in both WKY and GK rats, respectively (Table 1). In addition, there were no significant differences in the body weights among WKY, $\mathrm{WKY}+\mathrm{SAL}, \mathrm{GK}$, and GK + SAL rats when the rats were treated with different dosages of 50,100 , and $200 \mathrm{mg} / \mathrm{kg} /$ day SAL for 4 weeks. These results indicated that dosage of $100 \mathrm{mg} / \mathrm{kg} /$ day SAL is appropriate and has an effective hypoglycemic activity in diabetic GK rats.

\section{Chronic administration of $100 \mathrm{mg} / \mathrm{kg} /$ day SAL for 4 weeks significantly reduced systolic and diastolic blood pressure in diabetic GK rats}

As compared with control WKY rats, diabetic GK rats showed a significant increase in systolic (Fig. 1a) and diastolic blood pressure (Fig. 1b), which is consistence with previous report [21]. In Experiment I, chronic administration of $50 \mathrm{mg} / \mathrm{kg} /$ day SAL for 4 weeks did not affect the blood pressure in WKY or GK rats, respectively. In Experiment II, chronic administration of 100 $\mathrm{mg} / \mathrm{kg} /$ day SAL for 4 weeks significantly reduced the blood pressure in diabetic GK, whereas did not affect the blood pressure in control WKY rats. In Experiment III, chronic administration of $200 \mathrm{mg} / \mathrm{kg} /$ day SAL for 4 weeks significantly decreased blood pressure in both WKY and GK rats, respectively. These results indicated that dosage of $100 \mathrm{mg} / \mathrm{kg} /$ day SAL is effective for reducing blood pressure in diabetic GK rats.
Chronic administration of $100 \mathrm{mg} / \mathrm{kg} /$ day SAL for 4 weeks markedly inhibited the contractile activity of middle cerebral artery in diabetic GK rats

The endothelial layer was removed to rule out the endothelium-dependent relaxation. As compared with that in WKY rats, contractile responsiveness of middle cerebral artery to $\mathrm{KCl}$ (Figs. 2a and 3a) and 5-HT (Figs. 2b and $3 \mathrm{~b}$ ) both significantly increased in diabetic GK rats, which is in accordance with previous report [33]. In Experiment I, chronic treatment with $50 \mathrm{mg} / \mathrm{kg}$ /day SAL for 4 weeks had no obvious effects on contractile activity in WKY or Diabetic GK rats, respectively (Fig. 2), which indicated that $50 \mathrm{mg} / \mathrm{kg} /$ day SAL is not an effective dosage for reducing contractile activity in diabetic GK rats. In Experiment II, chronic administration of $100 \mathrm{mg} / \mathrm{kg} /$ day SAL for 4 weeks significantly decreased the contractile activity of middle cerebral artery to Ach (Figs. 2a and 3a) and SNP (Figs. 2b and 3b) in diabetic GK rats, respectively, whereas did not affect the contractile activity in control WKY rats. Under the condition of $60 \mathrm{mM} \mathrm{KCl}$, chronic administration of $100 \mathrm{mg} / \mathrm{kg} /$ day SAL markedly reduced the luminal diameter from $(-33.8 \pm 2.6) \%$ in GK rats to $(-28.0 \pm 2.1) \%$ in $\mathrm{GK}+\mathrm{SAL}$ rats (Fig. 2a). In addition, when the concentration of 5 - HT was $10^{-6} \mathrm{M}$, chronic administration of $100 \mathrm{mg} / \mathrm{kg} /$ day SAL significantly decreased the luminal diameter from $(-43.8 \pm 2.7) \%$ in $\mathrm{GK}$ rats to $(-35.3 \pm 3.6) \%$ in $\mathrm{GK}+\mathrm{SAL}$ rats (Fig. 2b). However, SAL treatment did not restore the contractile responsiveness in diabetic rats to the normal control level for there was also a significant difference in the contractile responsiveness of middle cerebral artery between GK+ SAL and WKY rats. When the control rats were treated with $100 \mathrm{mg} / \mathrm{kg} /$ day SAL, there were no significant differences in the contractile responsiveness of middle cerebral artery between WKY + SAL and WKY rats (Fig. 3). In Experiment III, chronic treatment with $200 \mathrm{mg} / \mathrm{kg} /$ day SAL for 4 weeks significantly decreased the contractile responsiveness in both WKY and Diabetic GK rats, respectively (Fig. 2). These results indicated that dosage of $100 \mathrm{mg} / \mathrm{kg} /$ day SAL is appropriate for reducing contractile activity of middle cerebral artery in diabetic GK rats. Therefore, we selected $100 \mathrm{mg} / \mathrm{kg} /$ day of SAL as the working dosage in the next animal study.

Chronic administration of $100 \mathrm{mg} / \mathrm{kg} /$ day SAL for 4 weeks markedly decreased the $\mathrm{Ca}_{\mathrm{L}}$ current densities of cerebral VSMCs isolated from diabetic GK rats

The inward currents were evoked by increasing depolarization from $-40 \mathrm{mV}$ to $+60 \mathrm{mV}$ (Fig. 4a). The mean current-voltage relationship $(I-V)$ curves were expressed in terms of current densities which were calculated by normalizing current to Cm (Fig. 4b) [27]. As compared with that in WKY, whole-cell $\mathrm{Ca}_{\mathrm{L}}$ currents of cerebral VSMCs are much bigger in diabetic GK rats, 
Table 1 Body weight and fasting blood glucose in WKY, WKY + SAL, GK, and GK + SAL rats in Experiment I, Experiment II, and Experiment III

\begin{tabular}{|c|c|c|c|c|}
\hline & \multicolumn{2}{|l|}{ 20-week of age } & \multicolumn{2}{|c|}{$\begin{array}{l}\text { 24-week of age } \\
\text { (4 weeks SAL treatment) }\end{array}$} \\
\hline & Body weight (g) & Blood glucose $(\mathrm{mM})$ & Body weight (g) & Blood glucose (mM) \\
\hline \multicolumn{5}{|l|}{ Experiment I } \\
\hline $\mathrm{WKY}(n=10)$ & $375.0 \pm 11.5$ & $5.2 \pm 1.7$ & $418.0 \pm 18.8$ & $5.2 \pm 1.3$ \\
\hline $\mathrm{WKY}+50 \mathrm{mg} / \mathrm{kg} /$ day $\operatorname{SAL}(n=10)$ & $383.8 \pm 10.2$ & $5.4 \pm 1.3$ & $409.5 \pm 15.5$ & $4.9 \pm 1.8$ \\
\hline $\mathrm{GK}(n=10)$ & $389.0 \pm 11.6$ & $9.2 \pm 2.4^{*}$ & $427.0 \pm 12.3$ & $11.6 \pm 1.9^{*}$ \\
\hline GK + 50 mg/kg/day SAL $(n=10)$ & $391.0 \pm 11.4$ & $8.6 \pm 2.1^{*}$ & $419.0 \pm 18.9$ & $10.2 \pm 1.3^{*}$ \\
\hline \multicolumn{5}{|l|}{ Experiment II } \\
\hline $\mathrm{WKY}(n=15)$ & $386.0 \pm 15$ & $5.26 \pm 1.2$ & $412.5 \pm 17.8$ & $5.8 \pm 0.9$ \\
\hline $\mathrm{WKY}+100 \mathrm{mg} / \mathrm{kg} /$ day SAL $(n=15)$ & $378.5 \pm 13$ & $5.4 \pm 2.2$ & $426.9 \pm 15.3$ & $5.7 \pm 1.2$ \\
\hline $\mathrm{GK}(n=15)$ & $392.0 \pm 18$ & $8.9 \pm 1.3^{*}$ & $431.3 \pm 16.3$ & $10.5 \pm 1.4^{*}$ \\
\hline $\mathrm{GK}+100 \mathrm{mg} / \mathrm{kg} /$ day $\operatorname{SAL}(n=15)$ & $387.0 \pm 17$ & $9.1 \pm 1.6^{*}$ & $425.0 \pm 11.2$ & $7.8 \pm 1.5^{\# *}$ \\
\hline \multicolumn{5}{|l|}{ Experiment III } \\
\hline $\mathrm{WKY}(n=10)$ & $378.0 \pm 11.0$ & $4.7 \pm 1.5$ & $408.0 \pm 17.2$ & $5.8 \pm 1.6$ \\
\hline $\mathrm{WKY}+200 \mathrm{mg} / \mathrm{kg} /$ day SAL $(n=10)$ & $383.2 \pm 13.6$ & $5.2 \pm 1.1$ & $415.5 \pm 16.5$ & $3.4 \pm 1.8^{*}$ \\
\hline $\mathrm{GK}(n=10)$ & $389.0 \pm 12.7$ & $8.5 \pm 1.2^{*}$ & $436.0 \pm 12.7$ & $11.2 \pm 1.5^{*}$ \\
\hline $\mathrm{GK}+200 \mathrm{mg} / \mathrm{kg} /$ day SAL $(n=10)$ & $393.0 \pm 16.5$ & $8.9 \pm 1.0^{*}$ & $428.0 \pm 15.2$ & $8.1 \pm 3.3^{\#^{*}}$ \\
\hline
\end{tabular}

WKY Control WKY rats, WKY + SAL WKY rats administrated with SAL, GK Diabetic GK rats, GK + SAL GK rats administrated with SAL. SAL was administrated with different dosage of 50, 100 and $200 \mathrm{mg} / \mathrm{kg} /$ day for 4 weeks in Experiment I, Experiment II, and Experiment III, respectively. ${ }^{*} P<0.05$ vs. WKY and ${ }^{\#} P<0.05$ vs. GK rats
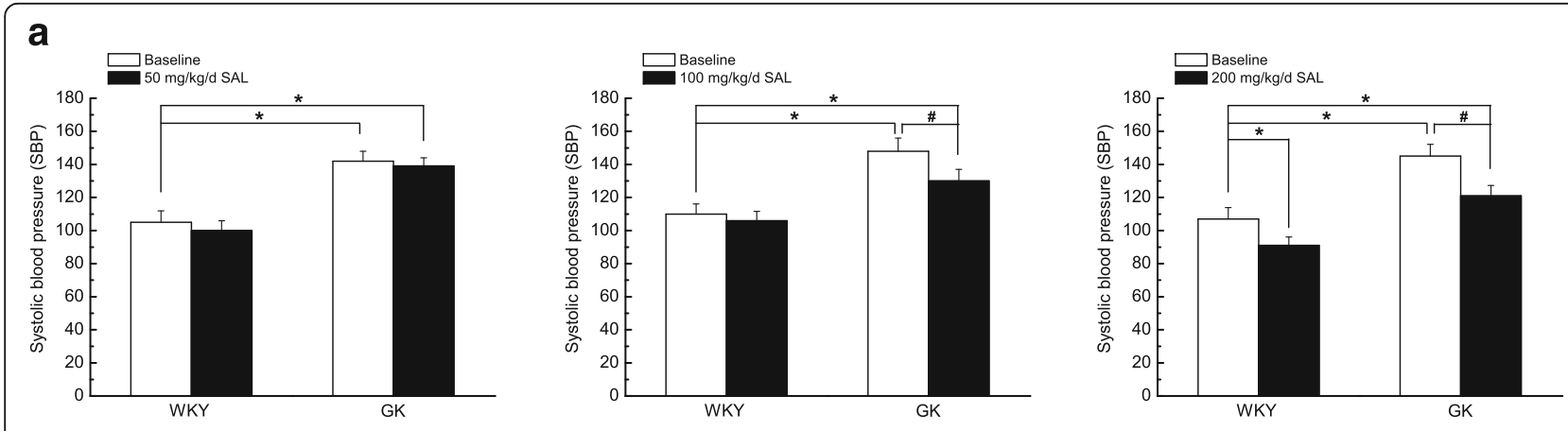

\section{b}
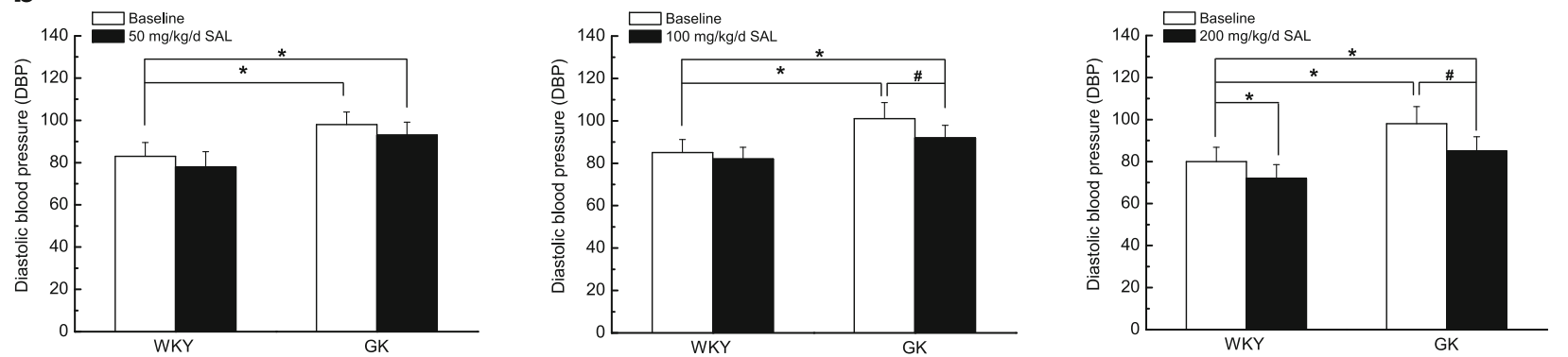

Fig. 1 Comparison of systolic (a) and diastolic blood pressure (b) from WKY, WKY + SAL, GK, and GK + SAL rats. SAL was administrated with different dosage of 50, 100 and $200 \mathrm{mg} / \mathrm{kg} /$ day for 4 weeks in Experiment I, Experiment II, and Experiment III, respectively. Chronic administration of $50 \mathrm{mg} / \mathrm{kg} / \mathrm{day}$ SAL had no obvious effects on systolic (a) and diastolic blood pressure (b) in WKY or GK rats, respectively. However, chronic administration of 100 mg/ $\mathrm{kg} /$ day SAL significantly reduced the blood pressure in diabetic GK, whereas did not affect the blood pressure in control WKY rats. In addition, chronic administration of $200 \mathrm{mg} / \mathrm{kg} /$ day SAL significantly decreased systolic (a) and diastolic blood pressure (b) in both WKY and GK rats, respectively. These results indicated that dosage of $100 \mathrm{mg} / \mathrm{kg} /$ day SAL is effective for lowering blood pressure in diabetic GK rats. Values are expressed as means \pm SEM and $n=10$ animals in each group. ${ }^{*} P<0.05$ vs. WKY rats and $\# P<0.05$ vs. GK rats 

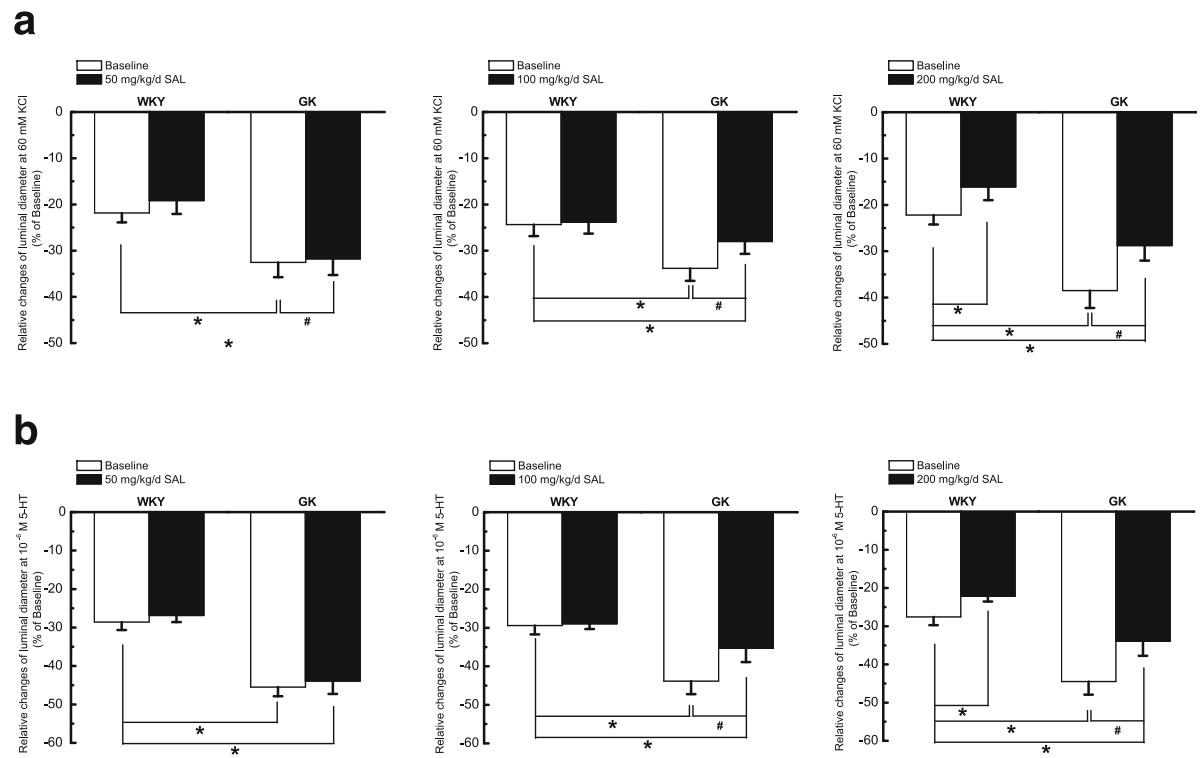

Fig. 2 Comparison of contractile function in response to $60 \mathrm{mM} \mathrm{KCl}$ (a) and $10^{-6} \mathrm{M}$ 5-hydroxytryptamine (5-HT, b) in middle cerebral artery isolated from WKY, WKY + SAL, GK, and GK + SAL rats, respectively. SAL was administrated with different dosage of 50, 100 and $200 \mathrm{mg} / \mathrm{kg} / \mathrm{day}$ for 4 weeks in Experiment I, Experiment II, and Experiment III, respectively. Chronic administration of $50 \mathrm{mg} / \mathrm{kg} /$ day SAL had no obvious effects on contractile responsiveness to $\mathrm{KCl}(\mathrm{A})$ and 5-HT (b) in WKY or GK rats, respectively. However, chronic administration of $100 \mathrm{mg} / \mathrm{kg} / \mathrm{day}$ SAL significantly inhibited the augmented contractile responsiveness to $\mathrm{KCl}(\mathbf{a})$ and $5-\mathrm{HT}(\mathbf{b})$ in GK rats, whereas did not change the contractile responsiveness in WKY rats. In addition, chronic administration of $200 \mathrm{mg} / \mathrm{kg} /$ day SAL significantly inhibited the contractile responsiveness to $\mathrm{KCl}$ (a) and 5-HT (b) in both WKY and GK rats, respectively. WKY: control WKY rats, WKY + SAL: control WKY rats administrated with SAL, GK: diabetic GK rats, GK + SAL: GK rats administrated with SAL. Values are expressed as means \pm SEM and $n=8$ animals in each group. ${ }^{*} P<0.05$ vs. WKY rats and $\# P<0.05$ vs. GK rats

which is consistent with the previous reports [22, 33]. Chronic administration of $100 \mathrm{mg} / \mathrm{kg} /$ day SAL significantly decreased the $\mathrm{Ca}_{\mathrm{L}}$ channel current densities of cerebral VSMCs isolated from diabetic GK rats. However, sAL treatment did not restore $\mathrm{Ca}_{\mathrm{L}}$ channel current densities to the normal control level for there was also a significant difference in $\mathrm{Ca}_{\mathrm{L}}$ channel current densities of cerebral VSMCs between GK + SAL and WKY rats. In addition, $100 \mathrm{mg} / \mathrm{kg} /$ day SAL had no effects in the $\mathrm{Ca}_{\mathrm{L}}$ channel current densities of cerebral VSMCs in WKY + SAL or WKY rats, respectively. These results clearly suggested that chronic SAL treatment significantly decreased the $\mathrm{Ca}_{\mathrm{L}}$ channel current densities of cerebral VSMCs isolated from diabetic GK rats.

Chronic administration of $100 \mathrm{mg} / \mathrm{kg} /$ day SAL for 4 weeks significantly reduced the expressions of $\mathrm{Ca}_{\mathrm{L}} \mathrm{a}_{1 \mathrm{C}}$-subunit at protein and mRNA levels in cerebral arteries isolated from diabetic GK rats

The protein expressions of $\mathrm{Ca}_{\mathrm{L}} \alpha_{1 \mathrm{C}}$-subunit $(240 \mathrm{kD})$ and $\beta$-actin $(42 \mathrm{kDa}$, the internal control) were shown in the membrane in Fig. 5a [28]. The relative protein and mRNA expressions of $\mathrm{Ca}_{\mathrm{L}} \alpha_{1 \mathrm{C}}$-subunit were shown in Fig. 5b and c, respectively. As compared with that in WKY rats, expressions of $\mathrm{Ca}_{\mathrm{L}} \alpha_{1 \mathrm{C}}$-subunit significantly increased in cerebral arteries of diabetic GK rats at protein and mRNA levels, respectively. Chronic administration of $100 \mathrm{mg} / \mathrm{kg} /$ day SAL significantly reduced the $\alpha_{1 C}$-subunit expressions in cerebral arteries of diabetic rats at both protein and mRNA levels. However, SAL treatment did not restore the $\alpha_{1 C^{-}}$-subunit expressions of diabetic GK rat to the normal control level for there were also significant differences in $\alpha_{1 \mathrm{C}}$-subunit expressions of $\mathrm{Ca}_{\mathrm{L}}$ channel in cerebral arteries between $\mathrm{GK}+$ SAL and WKY rats. When the WKY rats were treated with $100 \mathrm{mg} / \mathrm{kg} /$ day SAL, there were no significant differences in $\mathrm{Ca}_{\mathrm{L}} \alpha_{1 C^{-}}$-subunit expressions between $\mathrm{WKY}+\mathrm{SAL}$ and WKY rats. These results suggested that $100 \mathrm{mg} / \mathrm{kg} /$ day SAL treatment significantly reduced the $\alpha_{1 C^{-}}$subunit expressions of $\mathrm{Ca}_{\mathrm{L}}$ channel at protein and mRNA levels in cerebral arteries isolated from diabetic GK rats.

Acute application of SAL directly induced vasodilatation of cerebral artery isolated from normal WKY rats by inhibition of $\mathrm{Ca}_{\mathrm{L}}$ channel under hyperglycemia condition The middle cerebral artery was isolated from WKY rats and then the endothelial layer of middle cerebral artery was mechanically removed by the injection of air bubbles. As shown in Fig. 6, extracellular application of the hyperglycemia (D-glucose, $20 \mathrm{mM}$ for $10 \mathrm{~min}$ [26]) obviously induced the constriction of middle 


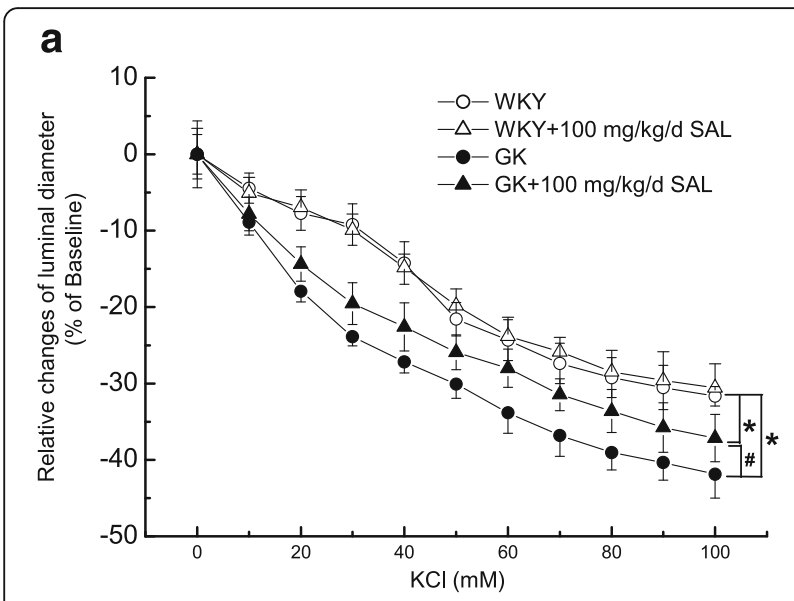

b

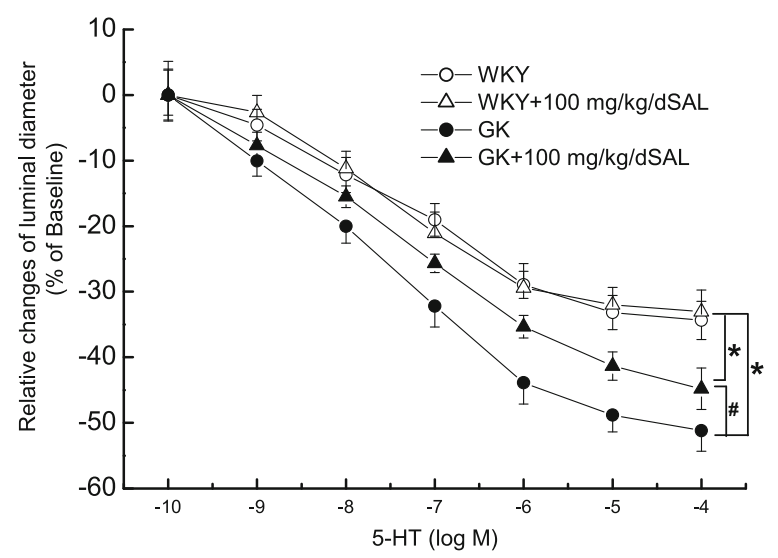

Fig. 3 Chronic administration of $100 \mathrm{mg} / \mathrm{kg} /$ day SAL significantly inhibited the contractile responsiveness of middle cerebral artery to cumulative superfusion of $\mathrm{KCl}(\mathbf{a})$ and 5-hydroxytryptamine (5-HT, b) in diabetic GK rats. Concentration-response relationships of middle cerebral artery were represented as the percentage of luminal diameter relative to the baseline internal diameter. WKY: control WKY rats, WKY + SAL: control WKY rats administrated with 100 mg/kg/ day SAL, GK: diabetic GK rats, GK + SAL: GK rats administrated with $100 \mathrm{mg} / \mathrm{kg} /$ day SAL. Values are expressed as means \pm SEM and $n=8$ animals in each group. ${ }^{*} P<0.05$ vs. WKY rats and $\# P<0.05$ vs. GK rats

cerebral artery. When the contraction reached the peak and kept in stable state, acute extracellular application of $100 \mu \mathrm{M}$ SAL (as described previously $[9,31]$ ) markedly induced the vascular relaxation in the presence of 20 mM D-glucose. Lastly, extracellular application of $5 \mu \mathrm{M}$ Bay $\mathrm{K}$ 8644, the specific agonist of $\mathrm{Ca}_{\mathrm{L}}$ channel, significantly blocked the SAL-induced relaxation of middle cerebral artery under hyperglycemia condition. These findings suggested that hyperglycemia induced cerebrovascular constriction and then the acute extracellular application of SAL could directly induce vasodilatation of cerebral artery by inhibition of $\mathrm{Ca}_{\mathrm{L}}$ channel under hyperglycemia condition.
Acute application of SAL directly inhibited the $\mathrm{Ca}_{\mathrm{L}}$ currents in cerebral VSMCs isolated from normal WKY rats under hyperglycemia condition

As shown in Fig. 7, acute application of high glucose evoked an increase in $\mathrm{Ca}_{\mathrm{L}}$ channel currents at $+10 \mathrm{mV}$ potential. Subsequently, acute application of $100 \mu \mathrm{M}$ SAL markedly reduced the amplitude of $\mathrm{Ca}_{\mathrm{L}}$ channel currents under $20 \mathrm{mM}$ D-glucose condition. Lastly, washing with $20 \mathrm{mM}$ D-glucose could diminish the effects of SAL on $\mathrm{Ca}_{\mathrm{L}}$ currents. These findings suggested that hyperglycemia increased the function of $\mathrm{Ca}_{\mathrm{L}}$ channel and then extracellular application of SAL directly reduced the function of $\mathrm{Ca}_{\mathrm{L}}$ in cerebral VSMCs under hyperglycemia condition.

\section{Treatment with SAL inhibited the MRNA expressions of $\mathrm{Ca}_{\mathrm{L}} \mathrm{a}_{1 \mathrm{C}}$-subunit and MLCK in cultured cerebral VSMCs under hyperglycemia condition}

Furthermore, we investigated the effects of SAL treatment on the expressions of $\mathrm{Ca}_{\mathrm{L}}$ channel and one of its downstream kinases, MLCK, in cultured cerebral VSMCs under hyperglycemia condition. As shown in Fig. 8, there was an increased mRNA expressions of $\mathrm{Ca}_{\mathrm{L}} \alpha_{1 C^{-}}$-subunit (Fig. 8a) and MLCK (Fig. 8b) in cultured cerebral VSMCs under hyperglycemia for $48 \mathrm{~h}$. However, the application with $100 \mu \mathrm{M}$ SAL for $48 \mathrm{~h}$ significantly decreased the mRNA expressions of $\mathrm{Ca}_{\mathrm{L}}$ $\alpha_{1 C^{-}}$-subunit and MLCK by 47 or $43 \%$ in cultured cerebral VSMCs under high glucose condition, respectively. It is interesting that blocking $\mathrm{Ca}_{\mathrm{L}}$ channel with $100 \mathrm{nM}$ nifedipine (the specific antagonist of $\mathrm{Ca}_{\mathrm{L}}$ channel) has similar effects to the treatment with SAL, which decreased the mRNA expressions of $\mathrm{Ca}_{\mathrm{L}} \alpha_{1 C^{-}}$-subunit and MLCK by 28 or $24 \%$ in cultured cerebral VSMCs under high glucose condition, respectively. Combination of SAL with nifedipine has no significant differences in the mRNA expressions of $\mathrm{Ca}_{\mathrm{L}} \alpha_{1 \mathrm{C}}$-subunit and MLCK as compared with SAL treatment alone in cultured cerebral VSMCs under high glucose condition. In contrast, application of Bay K 8644 (the specific agonist of $\mathrm{Ca}_{\mathrm{L}}$ channel) significantly increased the mRNA expressions of $\mathrm{Ca}_{\mathrm{L}} \alpha_{1 C^{-}}$-subunit and MLCK under high glucose condition, respectively. Combination of SAL with Bay K 8644 significantly inhibited the effects of Bay K 8644 in mRNA expressions of $\mathrm{Ca}_{\mathrm{L}} \alpha_{1 C^{-}}$-subunit and MLCK under high glucose condition, respectively. Our observations indicated that treatment with SAL could directly inhibit the mRNA expressions of $\mathrm{Ca}_{\mathrm{L}} \alpha_{1 \mathrm{C}^{-}}$-subunit and MLCK in cultured cerebral VSMCs under high glucose condition.

In addition, we investigated whether salidroside or nifedipine altered the channel expression in normal glucose conditions. As shown in Fig. 8c, application with $100 \mu \mathrm{M}$ SAL and $100 \mathrm{nM}$ nifedipine for $48 \mathrm{~h}$ significantly decreased the mRNA expressions of $\mathrm{Ca}_{\mathrm{L}}$ 


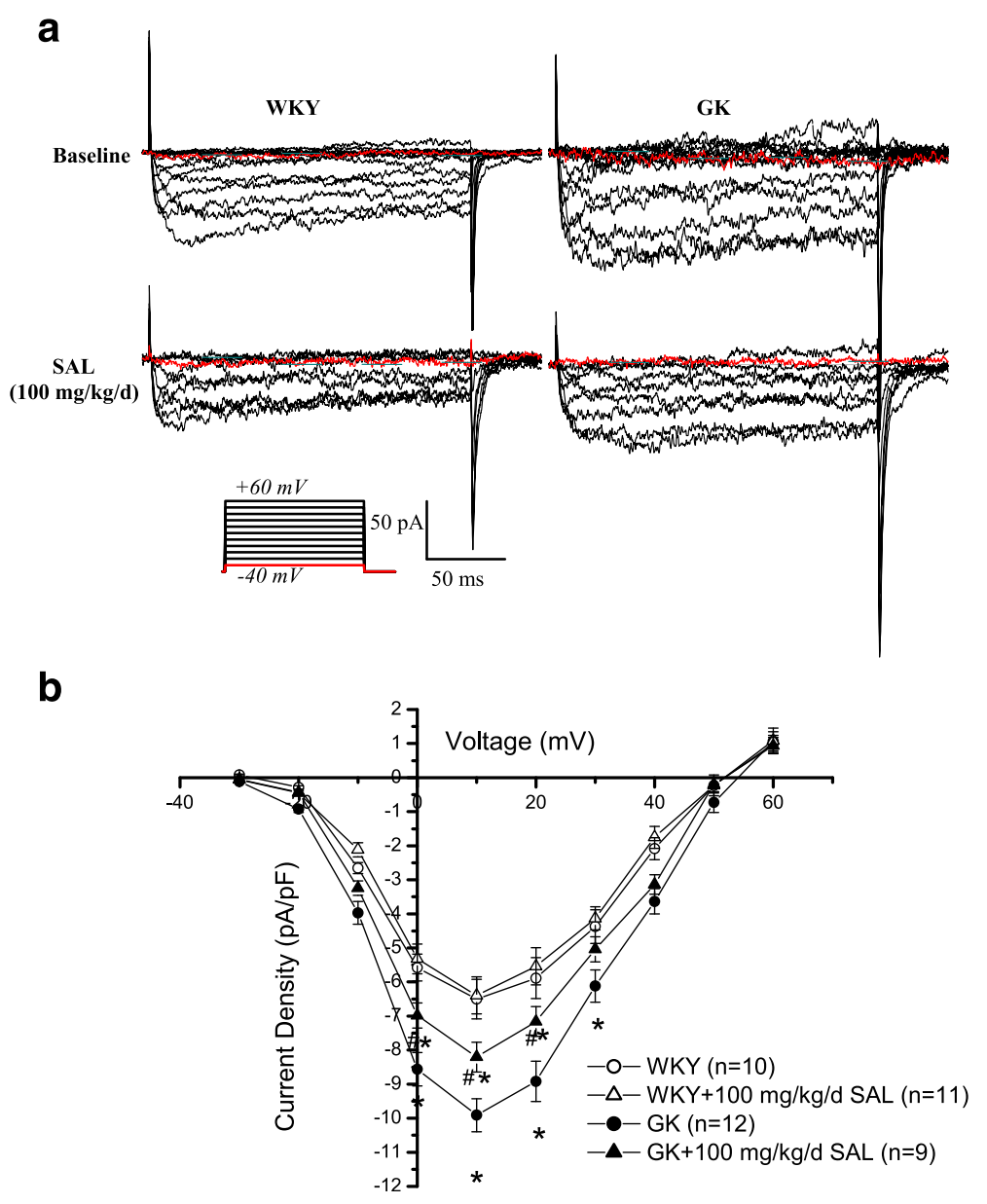

Fig. 4 Chronic administration of 100 mg/kg/day SAL markedly decreased whole-cell CaL current densities of cerebral VSMCS isolated from diabetic GK rats. Representative recording traces were used to show the whole-cell $\mathrm{Ca}_{L}$ currents $(\mathbf{a})$ and the mean $I-V$ curves were further expressed in terms of current densities (b) in WKY, WKY + SAL, GK, and GK + SAL rats. WKY: control WKY rats, WKY + SAL: control WKY rats administrated with $100 \mathrm{mg} / \mathrm{kg} /$ day SAL, GK: diabetic GK rats, GK + SAL: GK rats administrated with $100 \mathrm{mg} / \mathrm{kg} /$ day SAL. Values are means \pm SEM with the number of cells recorded in parentheses. ${ }^{*} P<0.05$ vs. WKY rats and $\# P<0.05$ vs. GK rats

a1C-subunit in cultured cerebral VSMCs under normal glucose condition, respectively. Combination of SAL with nifedipine has no significant differences in the mRNA expressions of $\mathrm{Ca}_{\mathrm{L}} \alpha 1 \mathrm{C}$-subunit as compared with SAL treatment alone in cultured cerebral VSMCs under normal glucose condition. In contrast, application of Bay K 8644 (the specific agonist of CaL channel) significantly increased the mRNA expressions of $\mathrm{Ca}_{\mathrm{L}} \alpha 1 \mathrm{C}$-subunit under normal condition, respectively. Combination of SAL with Bay K 8644 significantly inhibited the effects of Bay K 8644 in mRNA expressions of $\mathrm{Ca}_{\mathrm{L}} \alpha 1 \mathrm{C}$-subunit in normal glucose condition. These results indicated that $100 \mu \mathrm{M}$ SAL or $100 \mathrm{nM}$ nifedipine induced the similar effects on mRNA expressions of $\mathrm{Ca}_{\mathrm{L}} \alpha 1 \mathrm{C}$-subunit in normal or high glucose condition.

\section{Discussion}

There are two novel findings in the present work. First, chronic administration of $100 \mathrm{mg} / \mathrm{kg} /$ day SAL for 4 weeks not only lowered blood glucose, but also reduced blood pressure and alleviated cerebrovascular contractile activity in diabetic GK rats, which suggested that SAL treatment may provide a combinational therapy for lowering blood glucose and reducing blood pressure in diabetes at the same time. Secondly, SAL treatment markedly inhibited the function and expression of $\mathrm{Ca}_{\mathrm{L}}$ channel in cerebral VSMCs isolated from diabetic GK rats or when exposed to hyperglycemia condition, which may be the underlying mechanism responsible for the vascular protection of SAL in diabetes. Taken together, the present study provided evidences that SAL contributes to reducing blood pressure and alleviating cerebrovascular 


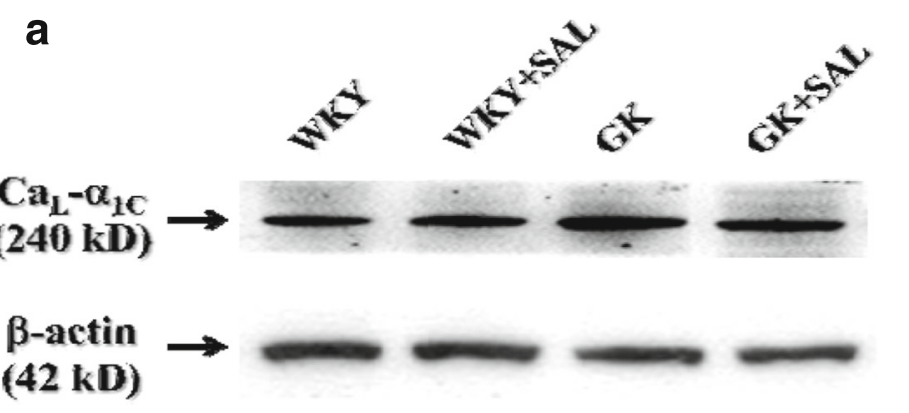

b
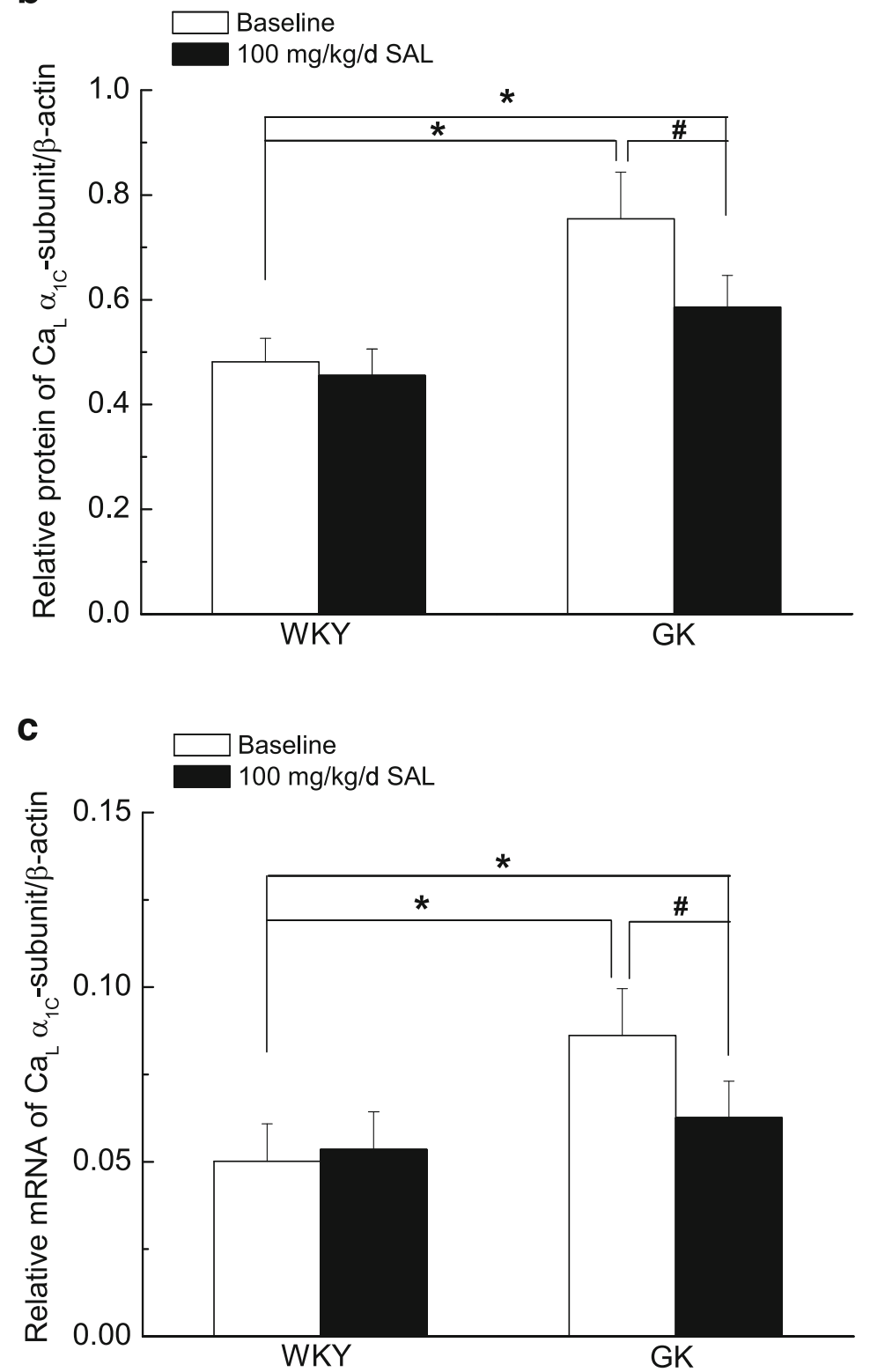

Fig. 5 (See legend on next page.) 
(See figure on previous page.)

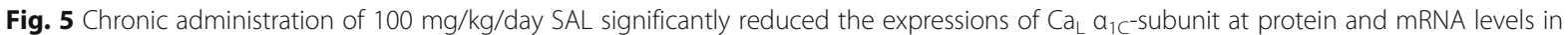
cerebral arteries isolated from diabetic GK rats. Representative band was used to show the protein expressions of CaL Channel in WKY, WKY + SAL, $G K$, and GK + SAL rats (a). Normalized band intensities of $\mathrm{Ca}_{\mathrm{L}} \mathrm{a}_{1} \mathrm{C}_{\text {-Subunit }}$ are shown as a percentage of the $\beta$-actin density (b). Relative mRNA of $\mathrm{Ca}_{\mathrm{L}} \mathrm{a}_{1}$ c-subunit are shown as a percentage of the $\beta$-actin mRNA (c). WKY: control WKY rats, WKY + SAL: control WKY rats administrated with $100 \mathrm{mg} /$ kg/day SAL, GK: diabetic GK rats, GK + SAL: GK rats administrated with $100 \mathrm{mg} / \mathrm{kg} /$ day SAL. Values are expressed as means \pm SEM from 4 independent experiments, and each sample based on tissue pooled from 3 to 4 animals. ${ }^{*} P<0.05$ vs. WKY rats and $\# P<0.05$ vs. GK rats

contractile activity in diabetic GK rats by inhibition of $\mathrm{Ca}_{\mathrm{L}}$ channel in smooth muscle cells, which might provide a novel approach to treat vascular complications in diabetic patients.

\section{Hyperglycemia, hypertension, and impaired $\mathrm{Ca}_{\mathrm{L}}$ channel in diabetic vascular complications}

Diabetes vascular complications are divided into microvascular and macrovascular complications. Microvascular complications are due to damage to small blood vessels including retinopathy, nephropathy, neuropathy, and diabetic foot disorders. Macrovascular complications are due to damage to larger blood vessels, such as heart attacks, strokes and, insufficiency in blood flow to legs [1]. Although the cellular mechanisms are complex, hyperglycemia and hypertension are considered to be two of the leading risk factors for vascular complications in diabetic patients [34]. It is well demonstrated in several randomized controlled trials and observational studies that hyperglycemia and hypertension frequently coexist, and their combination provides additive increases in the risk of life-threatening cardiovascular events in diabetes. Therefore, early recognition and treatment of both hyperglycemia and hypertension may remain central to delaying the onset and slowing the progress of diabetic vascular complication [7]. It is not clear why the diabetic subjects have an increased susceptibility to hypertension, but the mechanisms may involve impaired autoregulation and increased arterial contractility [35]. It is currently believed that increased arterial contractility and enhanced vascular tone in diabetes may arise from impaired $\mathrm{Ca}_{\mathrm{L}}$ channel function $[1,22]$.

$\mathrm{Ca}_{\mathrm{L}}$ channel is one of the important mediators to control arterial contraction by handling intracellular $\mathrm{Ca}^{2+}$ in VSMCs. When the membrane is depolarized, extracellular $\mathrm{Ca}^{2+}$ passes inward through $\mathrm{Ca}_{\mathrm{L}}$ channels and then triggers calcium release by activating ryanodine receptor 2 (RyR2). The increased intracellular $\mathrm{Ca}^{2+}$ binds with high affinity to calmodulin (CaM), a homolog of troponin C. The calcium-calmodulin complex causes calcium-dependent protein kinases to catalyse the phosphorylation of MLCK and then subsequently leads to the phosphorylation on ser19 and thr18 of MLC, resulting in the vascular contraction by the molecular motor activity of myosin and actin. Therefore, $\mathrm{Ca}_{\mathrm{L}}$ channels play a key role in regulating $\mathrm{Ca}^{2+}$ entry into
VSMCs and thus alterations in the activity of $\mathrm{Ca}_{\mathrm{L}}$ channel may strongly affect vascular contraction.

As compared with that in WKY rats, the diabetic GK rats showed a higher blood glucose level (Table 1) and an elevated blood pressure (Fig. 1) with a significant increased contractile activity of cerebral artery (Figs. 2 and 3 ) in the present study. In addition, the function (Fig. 4) and expressions (Fig. 5) of $\mathrm{Ca}_{\mathrm{L}}$ channel significantly increased in cerebral VSMCs isolated from diabetic GK rats. Correspondingly, we also observed that hyperglycemia directly induced the cerebrovascular contraction (Fig. 6) and enhanced the function of $\mathrm{Ca}_{\mathrm{L}}$ channel (Fig. 7) in cerebral VSMCs isolated from normal WKY rats. Furthermore, hyperglycemia could significantly increase the mRNA levels of $\mathrm{Ca}_{\mathrm{L}} \alpha_{1 \mathrm{C}}$-subunit and its downstream kinase, MLCK, in cultured cerebral VSMCs (Fig. 8). Our results are in agreement with previous reports that hyperglycemia impaired $\mathrm{Ca}_{\mathrm{L}}$ channel, which led to the increased contractility of arterial myocytes and enhanced vascular tone during diabetes mellitus $[1,26,36]$.

\section{The SAL treatment reduced blood pressure and alleviated cerebrovascular contractility in diabetic GK rats by inhibiting $\mathrm{Ca}_{\mathrm{L}}$ channel in VSMCs}

Rhodiola is a perennial plant which grows in the Arctic and high altitudes of Europe, Asia, and North America. Rhodiola has been used not only for high altitude-related symptoms, but also for improving physical and mental performance, reducing fatigue and depression, relieving vertigo and drowsiness, and alleviating chest tightness and palpitations [8]. SAL (p-hydroxyphenethyl- $\beta$-D-glucoside), a kind of phenylethanoid derivatives, is thought to be the most critical compounds extracted from Rhodiola. Recently, SAL has been demonstrated to have an obvious hypoglycemic effect in diabetes $[9,12]$ and a beneficial activity in diabetic vascular dysfunction [21]. For the hypoglycemic effects, Rhodiola crenulata extract has been demonstrated to exert the glucose-lowering effect partly by inhibiting hepatic gluconeogenesis through activating the AMPK signaling pathway [37]. Furthermore, it has been demonstrated that salidroside possessed hypoglycemic activity and protective effects against diabetes-induced oxidative stress [12]. In addition, salidroside has been reported to regulate lipid metabolism in type 2 diabetic mice by down-regulation of miR-370 of primary hepatocytes [38], improve the cellular metabolic flux by the activation of a mitochondria-related 

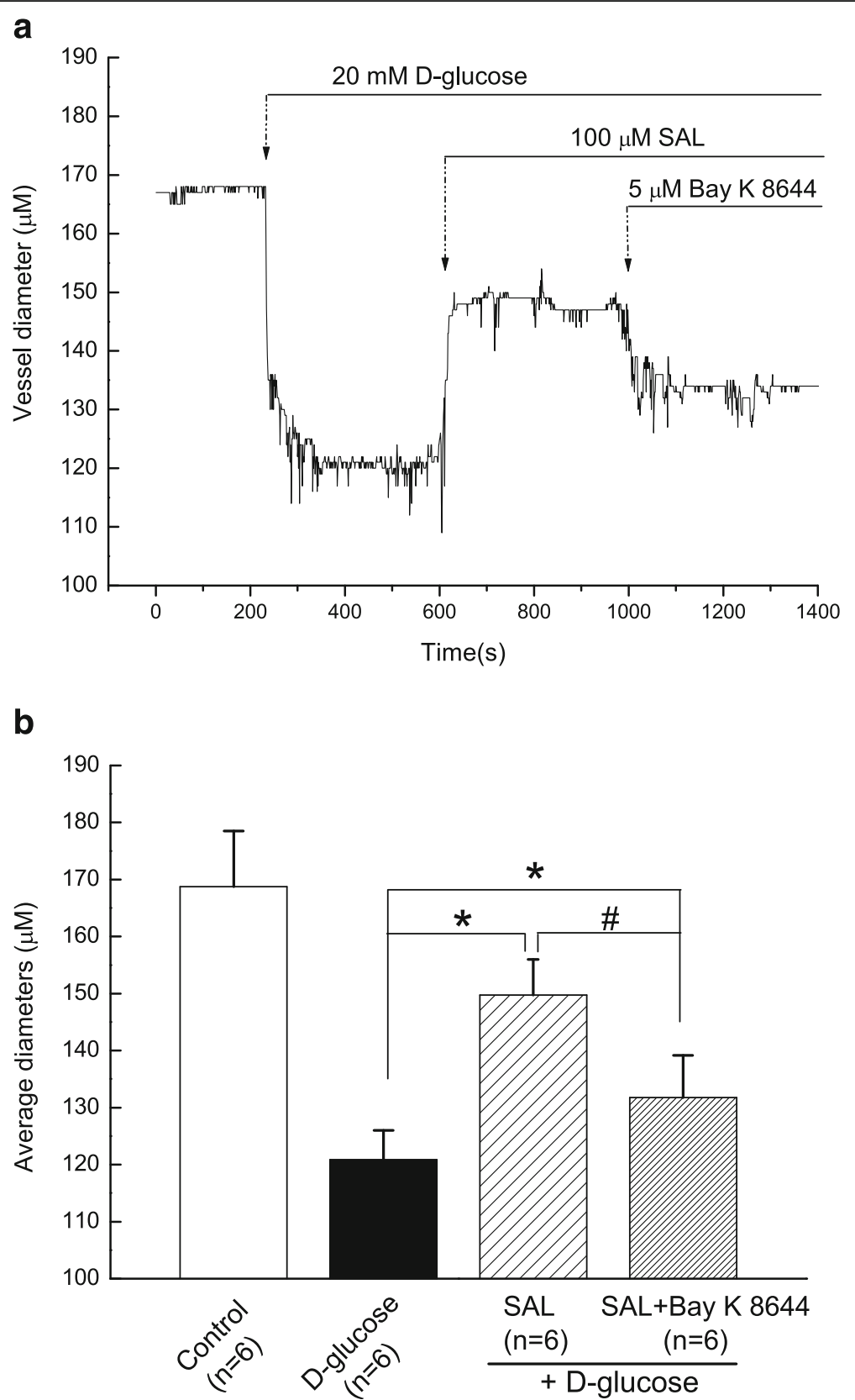

Fig. 6 Acute application of SAL directly induced vasodilatation of middle cerebral artery isolated from normal WKY rats by inhibition of CaL channel under hyperglycemia condition. Representative diameters of middle cerebral artery were recorded before and after application of $20 \mathrm{mM}$ D-glucose, $100 \mu \mathrm{M} \mathrm{SAL}$, and 5 MM Bay K 8644 (the specific agonist of Ca channel), respectively (a). Summary data for average diameters before and after application of 20 mM D-glucose, $100 \mu \mathrm{M} \mathrm{SAL}$, and 5 MM Bay K 8644 (b). 20 mM D-glucose induced the contraction of isolated middle cerebral artery ring and then $100 \mu \mathrm{M} \mathrm{SAL}$ was added as indicated dose when the contraction was stable. The SAL-induced relaxation was diminished by the addition of Bay $\mathrm{K} 8644$, the specific agonist of $\mathrm{Ca}_{\perp}$ channel. Values are means \pm SEM and $n=8$ from 6 animals. ${ }^{*} P<0.05$ vs. control condition and $\# P<0.05$ vs. high glucose condition

AMPK/PI3K/Akt/GSK3 $\beta$ pathway in hepatocytes [39], regulate glucose homeostasis in obese mice by repressing inflammation in white adipose tissues and improving leptin sensitivity in hypothalamus [15], stimulate glucose uptake in skeletal muscle cells by activating AMPK, and alleviate diabetic albuminuria by downregulation of caveolin-1 phosphorylation and inhibition of albumin transcytosis across glomerular endothelial cells [19].

In this study, chronic administration of $100 \mathrm{mg} / \mathrm{kg} / \mathrm{day}$ SAL not only significantly reduced glucose levels (Table 1 ), but also reduced blood pressure (Fig. 1) with a decreased contractile activity of cerebral artery (Figs. 2 and 3) in 


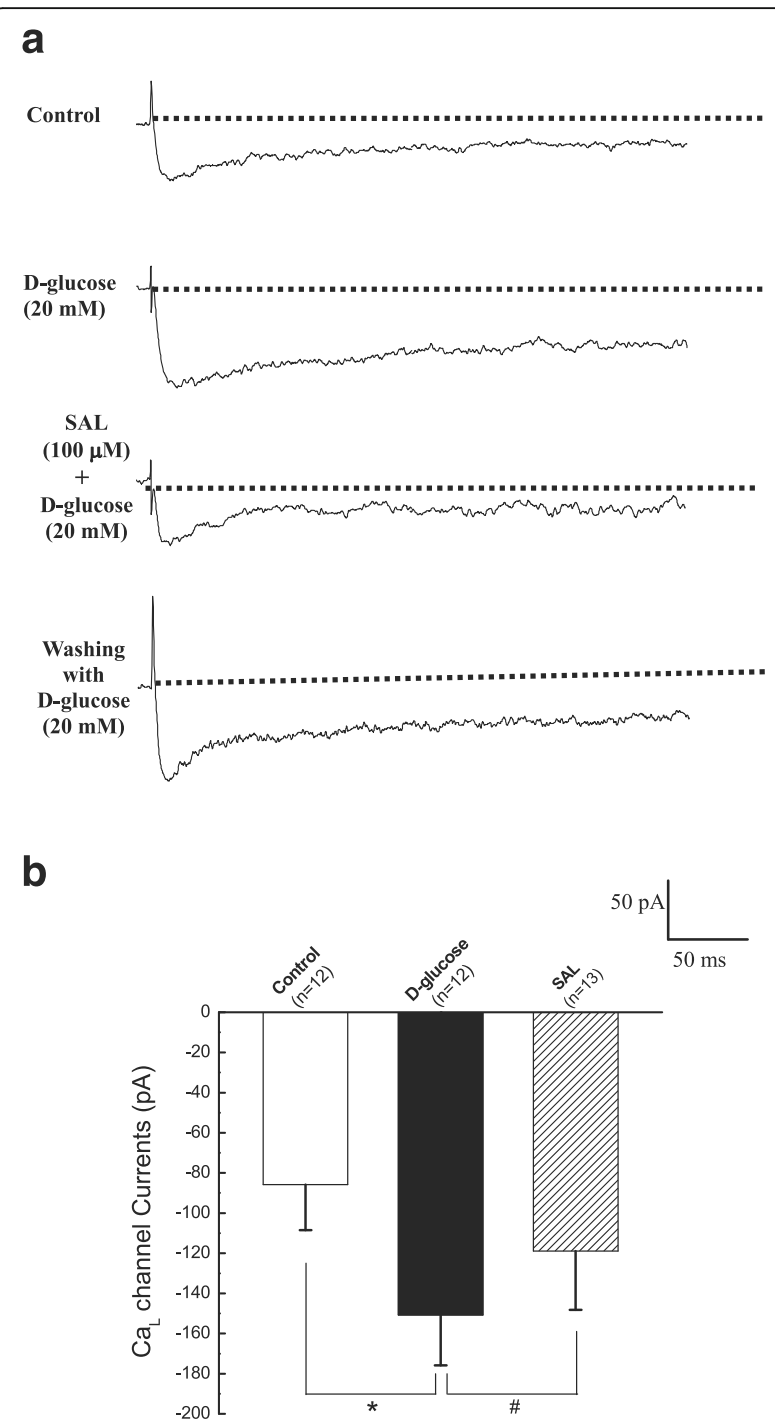

Fig. 7 Acute application of SAL directly inhibited the Ca $a_{L}$ currents in cerebral VSMCs isolated from normal WKY rats under hyperglycemia condition. Representative traces of $\mathrm{Ca}_{\mathrm{L}}$ channel current were recorded at $+10 \mathrm{mV}$ in cerebral VSMCs when exposed to $20 \mathrm{mM}$ D-glucose and then subsequent acute application of $100 \mu \mathrm{M} \mathrm{SAL}$ in the presence of 20 $\mathrm{mM}$ D-glucose. Lastly, washing with $20 \mathrm{mM}$ D-glucose could diminish the effects of SAL on CaL currents (A). Summarized data indicated the amplitudes of $\mathrm{Ca}_{\mathrm{L}}$ channel current at $+10 \mathrm{mV}$ before and after application of $20 \mathrm{mM}$ D-glucose and $100 \mu \mathrm{M}$ SAL, respectively. Values are means \pm SEM with the number of cells recorded in parentheses. ${ }^{*} P<0.05$ vs. control condition and $\# P<0.05$ vs. high glucose condition

diabetic GK rats. In addition, chronic administration of $100 \mathrm{mg} / \mathrm{kg} /$ day SAL not only significantly decreased the whole-cell current densities of $\mathrm{Ca}_{\mathrm{L}}$ channel (Fig. 4), but also reduced the expressions of $\mathrm{Ca}_{\mathrm{L}}$ channel $\alpha_{1 C^{-}}$-subunit at protein and mRNA levels (Fig. 5) in cerebral VSMCs of diabetic GK rats. Correspondingly, acute application of $100 \mu \mathrm{M}$ SAL could directly induce cerebrovascular vasodilatation (Fig. 6) and decreased the $\mathrm{Ca}_{\mathrm{L}}$ channel currents
(Fig. 7) in cerebral VSMCs isolated from control WKY rats under hyperglycemia condition. Furthermore, SAL significantly inhibited the mRNA levels of $\mathrm{Ca}_{\mathrm{L}} \alpha_{1 C^{-}}$-subunit and its downstream kinase, MLCK, in cultured cerebral VSMCs (Fig. 8). Our results clearly suggested SAL treatment alleviated cerebrovascular contractile activity in diabetic GK rats by inhibition of $\mathrm{Ca}_{\mathrm{L}}$ channel in VSMCs.

It has been reported that daily oral gavages with SAL $(40 \mathrm{mg} / \mathrm{kg}$ ) for 5 weeks did not change the blood pressure in diabetic GK rats [21], which is similar to our observation that administration of $50 \mathrm{mg} / \mathrm{kg} /$ day SAL for 4 weeks did not affect the blood pressure in GK rats in Experiment $I$. However, we also found that dosage of $100 \mathrm{mg} / \mathrm{kg} /$ day SAL is effective for lowering blood pressure in diabetic GK rats and dosage of $200 \mathrm{mg} / \mathrm{kg} /$ day SAL lowered blood pressure not only in diabetic GK rats but also in control WKY rats (Fig. 1). Therefore, the dosage of SAL is very important for the treatment in diabetic GK rats.

\section{Practical implications of the present study}

Several studies and new guidelines indicated that aggressive treatment of hypertension with 2 or more antihypertensive agents would reduce blood pressure and show a concomitant reduction of cardiovascular risk in diabetic subjects [5, 6]. For example, angiotensin-converting enzyme inhibitors, angiotensin-receptor blockers, thiazide diuretics, beta-adrenoreceptor blockers, and calciumchannel blockers, are effective antihypertensive agents in type 2 diabetes $[6,7]$. Here, we observed for the first time that SAL, a traditional herb, could provide a combinational therapy for lowering blood glucose (Table 1) and reducing blood pressure (Fig. 1) in diabetic GK rats at the same time. Therefore, SAL treatment could be a good alternative or at least supplement to treat DM by lowering blood glucose and reducing cardiovascular risk at the same time in diabetic patients. In addition, it has been demonstrated that impaired $\mathrm{Ca}_{\mathrm{L}}$ channel is associated with increased arterial contractility, which leads to the elevated blood pressure and reduced blood flow in diabetes $[1,22]$. Our work found that SAL treatment alleviated cerebrovascular contractility by directly inhibiting $\mathrm{Ca}_{\mathrm{L}}$ channel, which might be the underlying mechanism of SAL responsible for vascular protection in diabetes. Furthermore, inhibition of $\mathrm{Ca}_{\mathrm{L}}$ channel may provide a novel target for therapeutic intervention for diabetic vascular complications in diabetes.

\section{Limitations of the study}

Firstly, we did not investigate the concentration of salidroside in plasma after intragastric gavage (i.g) administration of $100 \mathrm{mg} / \mathrm{kg}$ salidroside in vivo in the present study. It is believed that $\beta$-glucosidases could hydrolyze the phenol glycoside to aglycone in the jejunum, and then aglycone are absorbed by the intestine or further 


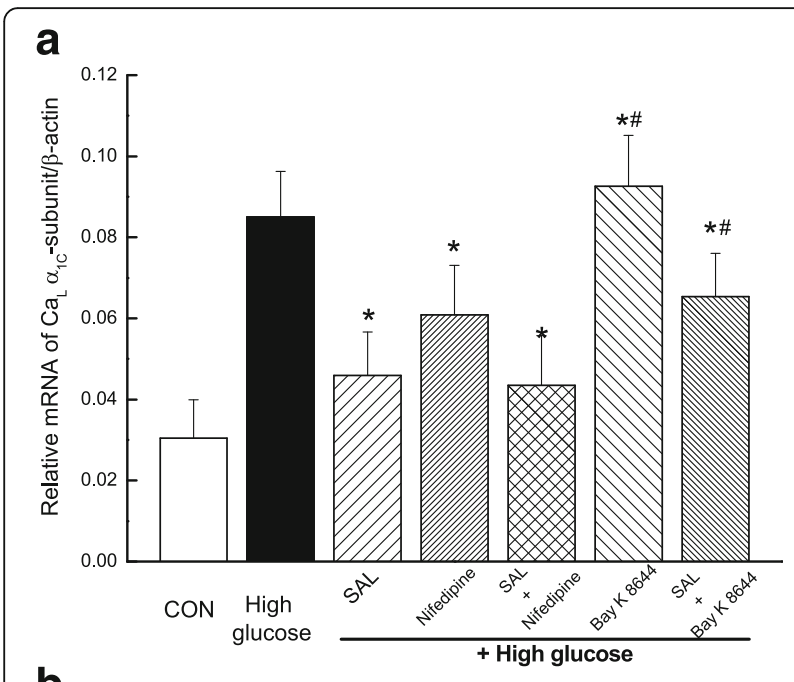

b

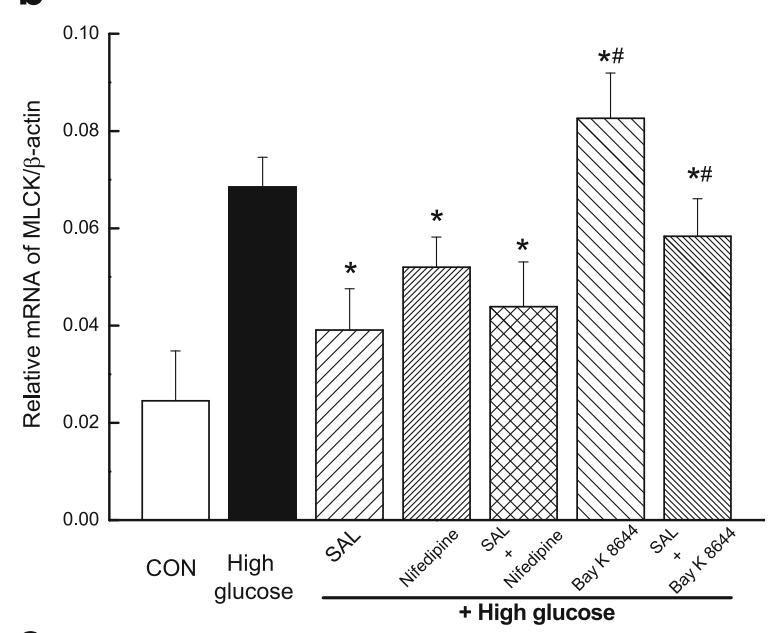

C

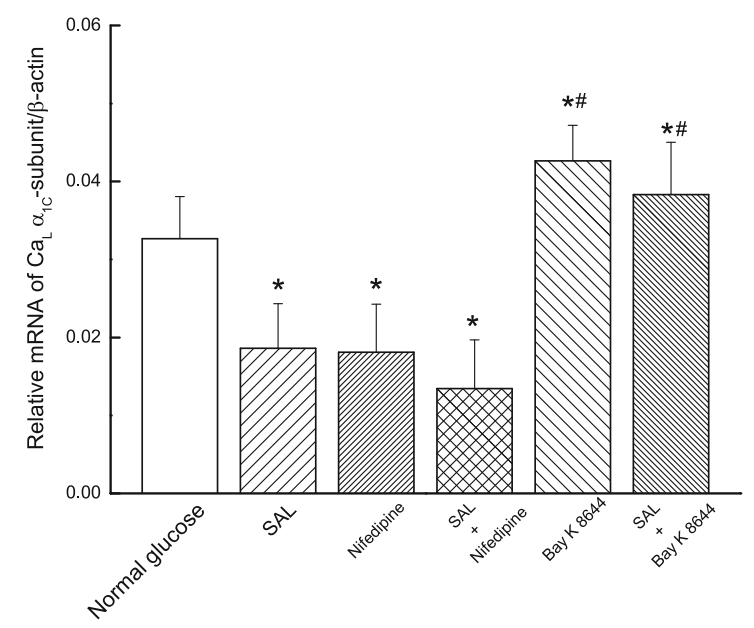

Fig. 8 Treatment with SAL for $48 \mathrm{~h}$ inhibited the mRNA expressions of $\mathrm{Ca}_{\mathrm{L}} \mathrm{a}_{1}$-subunit and MLCK in cultured cerebral VSMCS under high glucose condition. Relative mRNA levels of $C a_{L} a_{1}$-subunit (a) and MLCK (b) are shown as a percentage of the $\beta$-actin mRNA, respectively. It is shown the relative mRNA levels of CaL $a_{1}$-Subunit (c) in cultured cerebral VSMCS under normal glucose condition. Values are expressed as means \pm SEM from 4 independent experiments. ${ }^{*} P \leq 0.05$ as compared with high glucose control and \#P<0.05 vs. treatment with SAL treatment

metabolized into several other products before absorption by intestinal microflora [40]. It has been suggested that salidroside may metabolize to p-tyrosol, its sulfate or glucuronide conjugates, or even the methylate after i.g administration [41]. Furthermore, it has been reported that the absorption of salidroside in plasma reached the maximum within 20-30 min after i.g administration of $100 \mathrm{mg} / \mathrm{kg}$ salidroside and then decreased [41]. In animal study of present work, we administrated $100 \mathrm{mg} / \mathrm{kg} / \mathrm{day}$ salidroside by i.g to GK and control rats for 4 weeks to investigate blood pressure and the function of $\mathrm{Ca}_{\mathrm{L}}$ channel. In cell study of present study, we administrated $100 \mu \mathrm{M}$ salidroside to cultured cerebral VSMCs for $48 \mathrm{~h}$ under hyperglycemia in vitro. The concentration of salidroside $(100 \mu \mathrm{M})$ in our study is same to the previous report that $100 \mu \mathrm{M}$ salidroside blocks the proliferation of pulmonary artery smooth muscle cells (PASMCs) induced by plateletderived growth factor- $\mathrm{BB}$ in vitro [42]. In addition, the concentration of salidroside $(100 \mu \mathrm{M})$ in our study is also similar to the previous report that $800 \mu \mathrm{M}$ salidroside modulated cell apoptosis in mouse cultured pulmonary arterial smooth muscle cells (PASMCs) after chronic hypoxia exposure in vitro [10]. Secondly, Our results indicated that $100 \mu \mathrm{M}$ SAL or $100 \mathrm{nM}$ nifedipine induced the similar effects on mRNA expressions of $\mathrm{Ca}_{\mathrm{L}} \alpha 1 \mathrm{C}$-subunit in normal or high glucose condition (Fig. 8c). It has been reported that the sensitivities of $\mathrm{Ca}_{\mathrm{L}}$ currents to nifedipine or Bay K 8644 were altered in tail artery SMCs from streptozotocin-induced diabetic rats [43]. Until now, only we investigated that salidroside could alter the function and expression of $\mathrm{Ca}_{\mathrm{L}}$ channel in diabetes. In further work, it is very interesting to compare the effects of SAL and nifedipine on the expressions of $\mathrm{Ca}_{\mathrm{L}}$ in $\mathrm{GK}$ and normal rats in vivo.

\section{Conclusion}

There are two novel findings in the present work. First, chronic administration of $100 \mathrm{mg} / \mathrm{kg} /$ day SAL for 4 weeks significantly not only lowered blood pressure, but also reduced blood pressure and alleviated cerebrovascular contractile activity in diabetic GK rats, which suggested that SAL treatment might provide a combinational therapy for lowering blood glucose and reducing blood pressure in diabetes at the same time. Secondly, SAL treatment markedly inhibited the function and expression of $\mathrm{Ca}_{\mathrm{L}}$ channel in 
cerebral VSMCs isolated from diabetic GK rats or when exposed to hyperglycemia condition, which may be the underlying mechanism responsible for the vascular protection of SAL in diabetes. Taken together, the present study provided evidences that SAL contributes to reducing blood pressure and alleviating cerebrovascular contractile activity in diabetic GK rats by inhibition of $\mathrm{Ca}_{\mathrm{L}}$ channel in smooth muscle cells, which may provide a novel approach to treat vascular complications in diabetic patients.

\section{Additional files}

Additional file 1: Fig S1. Comparison of systolic (a) and diastolic blood pressure (b) from WKY, WKY + SAL, GK, and GK + SAL rats. (XLSX $11 \mathrm{~kb}$ )

Additional file 2: Fig S2. Comparison of contractile function in response to $60 \mathrm{mM} \mathrm{KCl}(\mathbf{a})$ and $10^{-6} \mathrm{M}$ 5-hydroxytryptamine $(5-\mathrm{HT}, \mathbf{b})$ in middle cerebral artery isolated from WKY, WKY + SAL, GK, and GK + SAL rats, respectively. (XLSX $11 \mathrm{~kb}$ )

Additional file 3: Fig S3. Chronic administration of $100 \mathrm{mg} / \mathrm{kg} /$ day SAL significantly inhibited the contractile responsiveness of middle cerebral artery to cumulative superfusion of $\mathrm{KCl}$ (a) and 5-hydroxytryptamine (5-HT, b) in diabetic GK rats. (XLSX $10 \mathrm{~kb}$ )

Additional file 4: Fig S4. Chronic administration of $100 \mathrm{mg} / \mathrm{kg} /$ day SAL markedly decreased whole-cell Ca $a_{L}$ current densities of cerebral VSMCS isolated from diabetic GK rats. (XLSX 9 kb)

Additional file 5: Fig S5. Chronic administration of $100 \mathrm{mg} / \mathrm{kg} /$ day SAL significantly reduced the expressions of $\mathrm{Ca}_{\llcorner} \mathrm{a}_{1} C^{-}$-subunit at protein and mRNA levels in cerebral arteries isolated from diabetic GK rats. (XLSX $9 \mathrm{~kb}$ )

Additional file 6: Fig S6. Acute application of SAL directly induced vasodilatation of middle cerebral artery isolated from normal WKY rats by inhibition of $\mathrm{Ca}_{L}$ channel under hyperglycemia condition. (XLSX 8 kb)

Additional file 7: Fig S7. Acute application of SAL directly inhibited the $\mathrm{Ca}_{\mathrm{L}}$ currents in cerebral VSMCS isolated from normal WKY rats under hyperglycemia condition. (XLSX $8 \mathrm{~kb}$ )

Additional file 8: Fig S8. Treatment with SAL for $48 \mathrm{~h}$ inhibited the

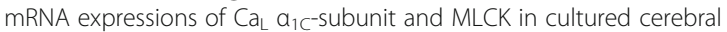
VSMCs under high glucose condition. (XLSX $9 \mathrm{~kb}$ )

\section{Abbreviations}

$\left[\mathrm{Ca}^{2+}\right]_{\text {i }}$ : Concentration of intracellular $\mathrm{Ca}^{2+} ; 5$-HT: 5-hydroxytryptamine; Ca: Longlasting voltage-dependent $\mathrm{Ca}^{2+}\left(\mathrm{L}-\right.$-type $\left.\mathrm{Ca}^{2+}\right)$ channel; $\mathrm{ClCR}: \mathrm{Ca}^{2+}$-induced $\mathrm{Ca}^{2+}$ release; DM: Diabetes mellitus; SAL: Salidroside; VSMCs: Vascular smooth muscle cells

\section{Funding}

This work was supported by National Natural Science Foundation of China (No. 31270904 and 81471032). The funders had no role in study design, data collection and analysis, decision to publish, or preparation of the manuscript.

\section{Availability of data and materials}

The datasets generated and analyzed during the current study are available in the Additional files 1, 2, 3, 4, 5, 6, 7 and 8 .

\section{Competing interests}

The authors declare that they have no competing interests.

\section{Authors' contributions}

Conceived and designed the experiments: Ma YG, Wang JW, and Xie MJ. Performed the experiments: Ma YG, Wang JW, Bai YG, Liu M, Dai ZJ. Analyzed the data: Wang JW, Liu M, Dai ZJ. Wrote the paper: Xie MJ. All authors read and approved the final version of the manuscript.

\section{Consent for publication}

Not applicable.

\section{Ethics approval}

Animal procedures were performed in adherence with the Guide for the Care and Use of Laboratory Animals published by the US National Institutes of Health (NIH Publication No. 85-23, revised 1996), with approval from Committee on the Ethics of Animal Experiments of the University of Xi'an Jiaotong University.

\section{Publisher's Note}

Springer Nature remains neutral with regard to jurisdictional claims in published maps and institutional affiliations.

\section{Author details}

${ }^{1}$ Department of Oncology, The Second Affiliated Hospital of Medical College, Xi'an Jiaotong University, Xi'an, Shaanxi Province 710004, China. ${ }^{2}$ Department of Cardiovascular Medicine, Shaanxi Provincial People's Hospital, Xi'an, Shaanxi 710068, China. ${ }^{3}$ Department of Aerospace Physiology, Key Laboratory of Aerospace Medicine of Ministry of Education, Fourth Military Medical University, Xi'an 710032, Shaanxi Province, China.

Received: 5 August 2016 Accepted: 1 April 2017

Published online: 26 April 2017

\section{References}

1. Fernández-Velasco M, Ruiz-Hurtado G, Gómez AM, Rueda A. Ca2+ handling alterations and vascular dysfunction in diabetes. Cell Calcium. 2014;56(5): 397-407.

2. Tousoulis D, Papageorgiou N, Androulakis E, Siasos G, Latsios G, Tentolouris K, Stefanadis C. Diabetes Mellitus-Associated Vascular Impairment. J Am Coll Cardiol. 2013;62(8):667-76.

3. Inzucchi S, Majumdar S. Glycemic targets: what is the evidence? Med Clin North Am. 2015;99(1):47-67.

4. Moghissi ES. Reexamining the evidence for inpatient glucose control: new recommendations for glycemic targets. Am J Health Syst Pharm. 2010;67(16 Suppl 8):S3-8.

5. Ettehad D, Emdin CA, Kiran A, Anderson SG, Callender T, Emberson J, Chalmers J, Rodgers A, Rahimi K. Blood pressure lowering for prevention of cardiovascular disease and death: a systematic review and meta-analysis. Lancet. 2016;387(10022):957-67.

6. Tillin T, Orchard T, Malm A, Fuller J, Chaturvedi N. The role of antihypertensive therapy in reducing vascular complications of type 2 diabetes. Findings from the Dlabetic REtinopathy Candesartan Trials-Protect 2 study. J Hypertens. 2011; 29(7):1457-62.

7. Zhao W, Katzmarzyk PT, Horswell R, Li W, Wang Y, Johnson J, Heymsfield SB, Cefalu WT, Ryan DH, Hu G. Blood pressure and heart failure risk among diabetic patients. Int J Cardiol. 2014;176(1):125-32.

8. Kosanovic D, Tian X, Pak O, Lai YJ, Hsieh YL, Seimetz M, Weissmann N, Schermuly RT, Dahal BK. Rhodiola: an ordinary plant or a promising future therapy for pulmonary hypertension? a brief review. Pulm Circ. 2013;3(3): 499-506.

9. Tao Zheng XYDW. Salidroside ameliorates insulin resistance through activation of a mitochondria-associated AMPK/PI3K/Akt/GSK3 $\beta$ pathway. Br J Pharmacol. 2015;13(172):3284-301

10. Huang X, Zou L, Yu X, Chen M, Guo R, Cai H, Yao D, Xu X, Chen Y, Ding C, et al. Salidroside attenuates chronic hypoxia-induced pulmonary hypertension via adenosine A2a receptor related mitochondria-dependent apoptosis pathway. J Mol Cell Cardiol. 2015;82:153-66.

11. Leung SB, Zhang H, Lau CW, Huang Y, Lin Z. Salidroside Improves HomocysteineInduced Endothelial Dysfunction by Reducing Oxidative Stress. Evid-Based Compl Alt. 2013;2013:1-8.

12. Li F, Tang H, Xiao F, Gong J, Peng Y, Meng X. Protective Effect of Salidroside from Rhodiolae Radix on Diabetes-Induced Oxidative Stress in Mice. Molecules. 2011;16(12):9912-24.

13. Panossian A, Wikman G, Sarris J. Rosenroot (Rhodiola rosea): traditional use, chemical composition, pharmacology and clinical efficacy. Phytomedicine. 2010;17(7):481-93.

14. Deciga-Campos M, Gonzalez-Trujano ME, Ventura-Martinez R, Montiel-Ruiz RM, Angeles-Lopez GE, Brindis F. Antihyperalgesic Activity of Rhodiola rosea in a Diabetic Rat Model. Drug Dev Res. 2016;77(1):29-36.

15. Wang M, Luo L, Yao L, Wang C, Jiang K, Liu X, Xu M, Shen N, Guo S, Sun C, et al. Salidroside improves glucose homeostasis in obese mice by repressing inflammation in white adipose tissues and improving leptin sensitivity in hypothalamus. Sci Rep. 2016;6:25399. 
16. Tang Y, Vater C, Jacobi A, Liebers C, Zou X, Stiehler M. Salidroside exerts angiogenic and cytoprotective effects on human bone marrow-derived endothelial progenitor cells via Akt/mTOR/p70S6K and MAPK signalling pathways. Brit J Pharmacol. 2014;171(9):2440-56.

17. Xing S, Yang X, Li W, Bian F, Wu D, Chi J, Xu G, Zhang Y, Jin S. Salidroside Stimulates Mitochondrial Biogenesis and Protects against $\mathrm{H} 2 \mathrm{O} 2$-Induced Endothelial Dysfunction. Oxid Med Cell Longev. 2014;2014:1-13.

18. Yin D, Yao W, Chen S, Hu R, Gao X. Salidroside, the main active compound of Rhodiola plants, inhibits high glucose-induced mesangial cell proliferation. Planta Med. 2009;75(11):1191-5.

19. Wu D, Yang X, Zheng T, Xing S, Wang J, Chi J, Bian F, Li W, Xu G, Bai X, et al. A Novel Mechanism of Action for Salidroside to Alleviate Diabetic Albuminuria: Effects on Albumin Transcytosis across Glomerular Endothelial Cells. Am J Physiol Endocrinol Metab. 2015;2015:391-2015.

20. Li HB, Ge YK, Zheng XX, Zhang L. Salidroside stimulated glucose uptake in skeletal muscle cells by activating AMP-activated protein kinase. Eur J Pharmacol. 2008;588(2-3):165-9.

21. Fajloun ZBJGG. The cardiovascular effects of Salidroside in the Goto-Kakizaki diabetic rat model. J Physiol Pharmacol. 2015;66(2):249-57.

22. Navedo MF, Takeda Y, Nieves-Cintron M, Molkentin JD, Santana LF. Elevated Ca2+ sparklet activity during acute hyperglycemia and diabetes in cerebral arterial smooth muscle cells. AJP: Cell Physiology. 2010;298(2):C211-20.

23. Dunn KM, Nelson MT. Calcium and diabetic vascular dysfunction. Focus on "Elevated Ca2+ sparklet activity during acute hyperglycemia and diabetes in cerebral arterial smooth muscle cells". AJP: Cell Physiology. 2010;298(2):C203-5

24. Xie MJ. Functional alterations in cerebrovascular $\mathrm{K}+$ and $\mathrm{Ca} 2+$ channels are comparable between simulated microgravity rat and SHR. Am J Physiol Heart Circ Physiol. 2005;289(3):H1265-76.

25. Lin LJ, Gao F, Bai YG, Bao JX, Huang XF, Ma J, Zhang LF. Contrasting effects of simulated microgravity with and without daily -Gx gravitation on structure and function of cerebral and mesenteric small arteries in rats. J Appl Physiol. 2009;107(6):1710-21.

26. Ma YG, Zhang YB, Bai YG, Dai ZJ, Liang L, Liu M, Xie MJ, Guan HT. Berberine alleviates the cerebrovascular contractility in streptozotocin-induced diabetic rats through modulation of intracellular $\mathrm{Ca}(2+)$ handling in smooth muscle cells. Cardiovasc Diabetol. 2016;15(1):63.

27. Xie MJ, Ma YG, Gao F, Bai YG, Cheng JH, Chang YM, Yu ZB, Ma J. Activation of BKCa channel is associated with increased apoptosis of cerebrovascular smooth muscle cells in simulated microgravity rats. Am J Physiol Cell Physiol. 2010;298(6):C1489-500.

28. Xue JH, Chen LH, Zhao HZ, Pu YD, Feng HZ, Ma YG, Ma J, Chang YM, Zhang ZM, Xie MJ. Differential regulation and recovery of intracellular Ca2+ in cerebral and small mesenteric arterial smooth muscle cells of simulated microgravity rat. PLoS One. 2011;6(5):e19775.

29. Chang $H, M a ~ Y$, Wang $Y$, Song Z, Li Q, Yang N, Zhao H, Feng $H$, Chang $Y$, $\mathrm{Ma}$ J, et al. High glucose alters apoptosis and proliferation in HEK293 cells by inhibition of cloned BKCa channel. J Cell Physiol. 2011;226(6):1660-75.

30. Sun Z, Cao X, Hu Z, Zhang L, Wang H, Zhou H, Li D, Zhang S, Xie M. MiR103 inhibits osteoblast proliferation mainly through suppressing Cav1.2 expression in simulated microgravity. Bone. 2015;76:121-8.

31. Sandu OA, Ragolia L, Begum N. Diabetes in the Goto-Kakizaki rat is accompanied by impaired insulin-mediated myosin-bound phosphatase activation and vascular smooth muscle cell relaxation. Diabetes. 2000;49(12):2178-89.

32. Zhang $M, L v X, L i J, X u Z$, Chen L. The Characterization of High-Fat Diet and Multiple Low-Dose Streptozotocin Induced Type 2 Diabetes Rat Model. Exp Diabetes Res. 2008;2008:1-9.

33. Pinho JF, Medeiros M, Capettini L, Rezende BA, Campos PP, Andrade SP, Cortes SF, Cruz JS, Lemos VS. Phosphatidylinositol 3-kinase- $\delta$ up-regulates Ltype Ca2+ currents and increases vascular contractility in a mouse model of type 1 diabetes. Brit J Pharmacol. 2010;161(7):1458-71.

34. Cheung BM, Li C. Diabetes and hypertension: is there a common metabolic pathway? Curr Atheroscler Rep. 2012;14(2):160-6.

35. Mancia G. The association of hypertension and diabetes: prevalence, cardiovascular risk and protection by blood pressure reduction. Acta Diabetol. 2005:42 Suppl 1:S17-25.

36. Velmurugan GV, White C. Calcium homeostasis in vascular smooth muscle cells is altered in type 2 diabetes by $\mathrm{BCl}-2$ protein modulation of InsP3R calcium release channels. Am J Physiol Heart Circ Physiol. 2011;302(1):H124-34.
37. Lee SY, Lai FY, Shi LS, Chou YC, Yen IC, Chang TC. Rhodiola crenulata extract suppresses hepatic gluconeogenesis via activation of the AMPK pathway. Phytomedicine. 2015;22(4):477-86.

38. Zhang XR, Fu XJ, Zhu DS, Zhang CZ, Hou S, Li M, Yang XH. Salidrosideregulated lipid metabolism with down-regulation of miR-370 in type 2 diabetic mice. Eur J Pharmacol. 2016;779:46-52.

39. Zheng T, Yang X, Wu D, Xing S, Bian F, Li W, Chi J, Bai X, Wu G, Chen X, et al. Salidroside ameliorates insulin resistance through activation of a mitochondria-associated AMPK/PI3K/Akt/GSK3beta pathway. Br J Pharmacol. 2015;172(13):3284-301.

40. loku K, Pongpiriyadacha Y, Konishi Y, Takei Y, Nakatani N, Terao J. Beta-Glucosidase activity in the rat small intestine toward quercetin monoglucosides. Biosci Biotechnol Biochem. 1998;62(7):1428-31.

41. Guo N, Hu Z, Fan X, Zheng J, Zhang D, Xu T, Yu T, Wang Y, Li H. Simultaneous determination of salidroside and its aglycone metabolite $\mathrm{p}$-tyrosol in rat plasma by liquid chromatography-tandem mass spectrometry. Molecules. 2012;17(4):4733-54.

42. Chen C, Tang Y, Deng W, Huang C, Wu T. Salidroside blocks the proliferation of pulmonary artery smooth muscle cells induced by plateletderived growth factorBB. Mol Med Rep. 2014;10(2):917-22.

43. Wang R, Wu Y, Tang G, Wu L, Hanna ST. Altered L-type Ca(2+) channel currents in vascular smooth muscle cells from experimental diabetic rats. Am J Physiol Heart Circ Physiol. 2000;278(3):H714-22.

\section{Submit your next manuscript to BioMed Central and we will help you at every step:}

- We accept pre-submission inquiries

- Our selector tool helps you to find the most relevant journal

- We provide round the clock customer support

- Convenient online submission

- Thorough peer review

- Inclusion in PubMed and all major indexing services

- Maximum visibility for your research

Submit your manuscript at www.biomedcentral.com/submit 